OPEN ACCESS

Edited by:

Sergio J. Ochatt,

INRA - UMR 1347 Agroécologie,

France

Reviewed by:

Zhongfu Ni,

China Agricultural University, China

Liezhao Liu,

Southwest University, China

${ }^{*}$ Correspondence:

Ganghua L

Igh@njau.edu.cn

Specialty section:

This article was submitted to Crop Science and Horticulture,

a section of the journal

Frontiers in Plant Science

Received: 23 February 2017 Accepted: 10 May 2017 Published: 30 May 2017

Citation:

Wu L, Zhang W, Ding Y, Zhang J, Cambula ED, Weng F, Liu Z, Ding C, Tang S, Chen L, Wang S and Li G (2017) Shading Contributes to the Reduction of Stem Mechanical Strength by Decreasing Cell Wall Synthesis in Japonica Rice (Oryza sativa L.). Front. Plant Sci. 8:881. doi: 10.3389/fp/s.2017.00881

\section{Shading Contributes to the Reduction of Stem Mechanical Strength by Decreasing Cell Wall Synthesis in Japonica Rice (Oryza sativa L.)}

Longmei Wu ${ }^{1,2,3}$, Wujun Zhang ${ }^{4}$, Yanfeng Ding ${ }^{1,2,3}$, Jianwei Zhang ${ }^{1,2,3}$,

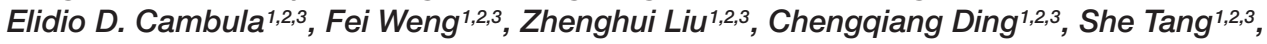
Lin Chen ${ }^{1,2,3}$, Shaohua Wang ${ }^{1,2,3}$ and Ganghua $\mathrm{Li}^{1,2,3 *}$

${ }^{1}$ College of Agronomy, Nanjing Agricultural University, Nanjing, China, ${ }^{2}$ Key Laboratory of Crop Physiology Ecology and Production Management, Ministry of Agriculture, Nanjing Agricultural University, Nanjing, China, ${ }^{3}$ Jiangsu Collaborative Innovation Center for Modern Crop Production, Nanjing Agricultural University, Nanjing, China, ${ }^{4}$ Chongqing Ratooning Rice Research Center, Chongqing Academy of Agricultural Sciences, Chongqing, China

Low solar radiation caused by industrial development and solar dimming has become a limitation in crop production in China. It is widely accepted that low solar radiation influences many aspects of plant development, including slender, weak stems and susceptibility to lodging. However, the underlying mechanisms are not well understood. To clarify how low solar radiation affects stem mechanical strength formation and lodging resistance, the japonica rice cultivars Wuyunjing23 (lodging-resistant) and W3668 (lodging-susceptible) were grown under field conditions with normal light (Control) and shading (the incident light was reduced by $60 \%$ ) with a black nylon net. The yield and yield components, plant morphological characteristics, the stem mechanical strength, cell wall components, culm microstructure, gene expression correlated with cellulose and lignin biosynthesis were measured. The results showed that shading significantly reduced grain yield attributed to reduction of spikelets per panicles and grain weight. The stem-breaking strength decreased significantly under shading treatment; consequently, resulting in higher lodging index in rice plant in both varieties, as revealed by decreased by culm diameter, culm wall thickness and increased plant height, gravity center height. Compared with control, cell wall components including non-structural carbohydrate, sucrose, cellulose, and lignin reduced quite higher. With histochemical straining, shading largely reduced lignin deposition in the sclerenchyma cells and vascular bundle cells compared with control, and decreased cellulose deposition in the parenchyma cells of culm tissue in both Wuyunjing23 and W3668. And under shading condition, gene expression involved in secondary cell wall synthesis, OsPAL, OsCOMT, OsCCoAOMT, OsCCR, and OsCAD2, and primary cell wall synthesis, OsCesA1, OsCesA3, and 
OsCesA8 were decreased significantly. These results suggest that gene expression involved in the reduction of lignin and cellulose in both sclerenchyma and parenchyma cells, which attribute to lignin and cellulose in culm tissue and weak mechanical tissue, consequently, result in poor stem strength and higher lodging risks.

\section{Highlights:}

(1) Shading decreases the stem mechanical strength of japonica rice by decreasing nonstructural carbohydrate, sucrose, lignin, and cellulose accumulation in culms.

(2) The decrease of carbon source under shading condition is the cause for the lower lignin and cellulose accumulation in culm.

(3) The expression of genes involved in lignin and primarily cell wall cellulose biosynthesis (OsCesA1, OsCesA3, and OsCesA8) at the stem formation stage are down-regulated under shading condition, inducing defective cell wall development and poor lodging resistance.

\section{Keywords: Japonica rice (Oryza sativa L.), lodging, shading, sucrose, cellulose, lignin, cell wall synthesis}

\section{INTRODUCTION}

Rice is a photoautotrophic crop and therefore relies on sunlight to generate carbohydrates to engage in growth and development. In recent decades, with increasing aerosol emissions due to industrial pollution, solar radiation has unfortunately decreased (global dimming) with a trend of $0.54 \mathrm{Wm}^{2} \mathrm{yr}^{-1}$ in South Asia (Stanhill and Cohen, 2001; Ramanathan and Feng, 2009; Kambezidis et al., 2012). Due to strong anthropogenic activities and air pollution in China, solar radiation is decreasing in most regions (Yang et al., 2013; Fu et al., 2015; Liu J. et al., 2015). This is especially true in China's primary area, from $25^{\circ} \mathrm{N}$ to $45^{\circ} \mathrm{N}$, where the solar radiation declined by $1.4 \sim 2.7 \%$ per decade (Stanhill and Cohen, 2001). Nevertheless, solar dimming is reducing the light intensity within plant canopies, and the light intensity plays vital roles in stem elongation and development. Low solar radiation significantly decreases the photosynthetically active radiation (PAR) in the rice canopy. As reported, shading results in more slender stems upon elongation and reduced whole-plant mechanical stability (Huber et al., 2014); shading increased the lodging rate, and an increase in the light intensity increased the stalk strength and decreased lodging in maize (Xue et al., 2016). Therefore, we hypothesized that shading may influence rice stem mechanical strength and thus will affect susceptibility to lodging.

Lodging is defined as the permanent displacement of plant stems from a vertical position, and it is caused by a loss of balance due to many internal and natural factors. Lodging primarily occurred at the basal internode, including the third or fourth internode from the top. Many researchers have reported the relationship between lodging and related traits. Plant height reduction was successful at improving lodging resistance during the "Green Revolution" (Khush, 1999). The plant height and gravity center height were major morphological characteristics that affected lodging resistance (Chandler, 1969). However, the plant height was reportedly not the primary lodging-related factor among varieties, and the culm width and thickness were also identified as important morphological traits associated with lodging resistance in wheat (Zuber et al., 1999). In previous research, the stiffness of the basal internode and the culm width, culm thickness, and well-developed mechanical tissues contributed to stem mechanical strength or lodging resistance. Furthermore, the mechanical strength of the basal internode primarily depends on carbohydrates, such as non-structural carbohydrates and structural carbohydrates (primarily lignin and cellulose). From the start of rice grain filling, non-structural carbohydrates are generally more easily transported to grains for grain filling, so a plant's mechanical strength primarily depends on having more structural carbohydrates (e.g., lignin and cellulose) in the basal stems (Zhang et al., 2014). As mentioned before, despite the complexity of lodging influencing factors, cellulose and lignin are two major structural carbohydrates of secondary cell walls in vascular plants, and they are well-known for being primarily responsible for stem mechanical strength. A significant correlation was found between the cellulose or lignin accumulation and the mechanical strength of rice (Zhang et al., 2014, 2016a), wheat (Peng et al., 2014), and buckwheat (Wang C. et al., 2015). The accumulation of lignin and the cellulose of culms in lodging rice varieties were lower than that in lodging-resistant varieties (Zhang et al., 2016a).

Environment factors including fertilizer, such as nitrogen application, as well as the light intensity regulate the biosynthesis and accumulation of lignin or cellulose in plants. For example, the light intensity up-regulated the phenylpropanoid (which is the origin of lignin biosynthesis) biosynthesis genes in tea callus; the phenylpropanoid accumulation increased (Wang et al., 2012b), promoting the lignin content in the cell walls of soybean hypocotyls ( $\mathrm{Su}$ et al., 2005). It was also reported that low light intensity decreased the lignin content in tea (Wang et al., 2012a), reduced the cellulose content in cotton (Chen et al., 2014), increased lodging risk in wheat (Sparkes and King, 2008), etc. In rice, previous studies have assessed 
how artificial shading regulates starch pasting characteristics (Wang et al., 2013), grain filling (Wang L. et al., 2015), yield reduction (Mo et al., 2015), and internode elongation in rice (Liu et al., 2016). However, shading treatment from elongation to heading (the key period of stem formation) affects the physical strength of the rice basal internodes. The way in which lignin or cellulose biosynthesis and accumulation in culms are impacted by shading treatments is not clear. The objectives of the present study was to investigate the effects of shading on rice lodging behavior from the jointing to heading stages by observing the morphological characteristics and microstructure characteristics of the second basal internodes, non-structural carbohydrates, sucrose, lignin and cellulose biosynthesis and accumulation, and their relationships to lodging resistance.

\section{MATERIALS AND METHODS}

\section{Plant Materials and Growth Conditions}

A field experiment was conducted at Baolin village, Danyang County, Jiangsu province $\left(31^{\circ} 54 \mathrm{~N}, 119^{\circ} 28 \mathrm{E}\right)$ in 2015 and 2016. The soil was an Orthic Acrisol with a total nitrogen content of $1.08,1.20 \mathrm{~g} \mathrm{~kg}^{-1}$, available phosphorus of 13.5 , $12.6 \mathrm{mg} \mathrm{kg}^{-1}$, available potassium of $109.8,105.6 \mathrm{mg} \mathrm{kg}$, organic matter of $20.8,20.2 \mathrm{~g} \mathrm{~kg}^{-1}$, and a $\mathrm{pH}$ of $6.8,6.6 \mathrm{in}$ 2015 and 2016, respectively. The experiments were arranged in a split-plot design with three replications. The area of each plot was $24 \mathrm{~m}^{2}$. In each plot, the average spacing was 25 hills per $\mathrm{m}^{2}(13.3 \mathrm{~cm} \times 30 \mathrm{~cm})$, with three seedlings per hill.

Two japonica rice cultivars, namely Wuyunjing23 (lodginginsensitive) and W3668 (lodging-sensitive), were used in this experiment. When the second basal internodes emerged (jointing stage), shading treatments were imposed on selected plots with black sun-shading net, which reduced the incident light by $60 \%$ (Shading), and there was a control with no shading (Control). The shading treatment was implemented from the elongation to the heading stages. The shading cloths were removed at the heading stage of rice population. In each year, seeds were sown in nursery boxes on 28 May and the seedlings were transplanted on 18 June in 2015 and sown in nursery boxes on 30 May and the seedlings were transplanted on 21 June in 2016. The nitrogen application rate, $180 \mathrm{~kg} \mathrm{~N} \mathrm{ha}^{-1}$ as urea, was applied four times (basal fertilizer was applied 1 day before transplanting, tillering fertilizer was applied 7 days after transplanting, topdressing nitrogen was applied at the panicle initiation stage and when the second leaf from the top was fully extended) by using $30 \%, 30 \%, 20 \%$, and $20 \%$ in each stage, respectively. Phosphorus with $90 \mathrm{~kg} \mathrm{P}_{2} \mathrm{O}_{5} \mathrm{ha}^{-1}$ as single superphosphate was applied as basal fertilizer 1 day before transplanting, and potassium with $120 \mathrm{~kg} \mathrm{~K}_{2} \mathrm{O} \mathrm{ha}^{-1}$ as potassium chloride was provided in two applications (1 day pre-transplantation and panicle initiation stage) by using $50 \%$ and $50 \%$ at each stage in all plots. Water, weeds, insects, and disease were controlled in accordance with local routine management to avoid yield loss.

\section{Measurement of Grain Yield and Yield Components, Culm Diameter, Culm Wall Thickness, Gravity Center Height and Plant Height}

At maturity, japonica rice grain yields (14.5\% moisture content) were measured within five hills according to the average tillers from each plot. The grain moisture content was measured using a moisture detector (GAC2100AGRI, DICKEY-john, Minneapolis city, MN, United States). Spikelets per panicle, spikelets fertility and spikelets per $\mathrm{m}^{2}$ were measured. The panicles were handthreshed and the filled grains were separated by submerging them in tap water. The filled grains were then oven-dried at $70^{\circ} \mathrm{C}$ to constant weight for determining grain weight. Culm diameter and culm wall thickness were measured with a digital caliper (accuracy of $0.01 \mathrm{~mm}$ ) at the middle of the fourth internode from the top. Plant height was measured with a ruler from the base to the tip of the panicle excluding awns for at least 15 representative main stems. Gravity center height refers to the distance from the culm base to the balance fulcrum with panicle, leaf, and sheath.

\section{Measurement of Lodging-Related Index and Stem Physical Properties}

Lodging-related traits and morphological parameters were determined at 20 days after heading. At least 10 main stems were collected and used for analysis. The lodging index and stem physical properties included the bending load, SL (the length from the broken point to the panicle top), FW (the fresh weight from the broken point to the panicle top). The bending load was measured at the fourth internodes from the top with AIKON (RX-5, Japan) at a distance of $6 \mathrm{~cm}$ according to a previous report (Ookawa, 1992). The lodging-related parameters were collected according to Ookawa's description (Ookawa et al., 2010) as follows: (1) Bending moment by whole plant (g.cm) $=\mathrm{SL}$ $(\mathrm{cm}) \times \mathrm{FW}(\mathrm{g}) ;(2)$ Breaking strength $(\mathrm{g} . \mathrm{cm})=1 / 4 \times$ breaking load $(\mathrm{Kg}) \times \mathrm{L}$ (Distance between fulcra $\left.(\mathrm{cm}) \times 10^{3}\right) ;(3)$ Lodging index $(\%)=$ Bending moment by whole plant (g.cm)/Breaking strength (g.cm) $\times 100$; (4) Cross-section modulus $\left(\mathrm{mm}^{3}\right)=\pi / 32 \times\left(\mathrm{a}_{1}{ }^{3} \mathrm{~b}_{1}-\mathrm{a}_{2}{ }^{3} \mathrm{~b}_{2}\right) / \mathrm{a}_{1}$, where $\mathrm{a}_{1}$ is the outer diameter of the minor axis and $a_{2}$ is the inner diameter of the minor axis; $b_{1}$ is the outer diameter of the major axis and $b_{2}$ is the inner diameter of the major axis; and (5) Bending stress $\left(\mathrm{g} \mathrm{mm}^{-2}\right)=$ Breaking strength/Cross section modulus.

\section{Scanning Electron Microscopy}

The second basal internodes were collected at heading stage and fixed in $3 \%$ glutaraldehyde. The samples were prepared according to Mou's description (Mou et al., 2000), with some modifications. Approximately $100 \mu \mathrm{m}$ hand-cut transverse sections were critical point-dried, sputter-coated with gold, then imaged with a scanning electron microscope (S-3000N; Hitachi, Tokyo, Japan). 


\section{Histochemical Staining of Transverse Sections}

The fourth internodes from the top were collected at the heading stage and fixed in FAA solution (70\% ethanol, $90 \mathrm{ml}$; acetic acid, $5 \mathrm{ml}$; and formaldehyde, $5 \mathrm{ml}$ ). To observe the lignified cell walls, phloroglucinol staining was performed according to standard protocols (Ookawa et al., 2014). First, the approximately $100 \mu \mathrm{m}$ hand-cut sections were treated with $1 \%$ phloroglucinol solution (ethanol: water $=7: 3(\mathrm{~V} / \mathrm{V})$; Sigma) for $10 \mathrm{~min}$, washed with $18 \% \mathrm{HCl}$ for $5 \mathrm{~min}$ and then observed using fluorescence microscopy (Leica, Wetzlar, Germany) under a light microscope. For the cellulose accumulation observation, the approximately $100 \mu \mathrm{m}$ transverse sections were treated with $0.05 \%$ calcofluor white (Sigma) for $2 \mathrm{~min}$ and then observed using a fluorescent microscope (Leica, Wetzlar, Germany).

\section{Measurement of Non-structural Carbohydrate, Sucrose, Lignin, and Cellulose Contents}

The fourth internodes from the top were collected at 20,10 days before heading; and 0,20 days after heading, oven-dried at $105^{\circ} \mathrm{C}$ for $30 \mathrm{~min}$ and then oven-dried at $70^{\circ} \mathrm{C}$ to a constant weight, and then milled into powder to determine the non-structural carbohydrate, sucrose, lignin, and cellulose contents. The nonstructural carbohydrate, sucrose, lignin, and cellulose content measurements were described by Updegraff (1969); Yoshida et al. (1976), Ishimaru et al. (2008), and Zhang et al. (2016a), respectively.

The non-structural carbohydrate content determination was performed using the following procedure: in brief, $0.1 \mathrm{~g}$ of each dried homogenized stem sample was extracted with distilled water for $2 \mathrm{~h}$ with boiling, and then they were extracted with perchloric acid $(9.2 \mathrm{~mol} / \mathrm{L})$ three times. Anthrone colorimetry reagents were added to the extract and then a spectrophotometer was used to measure the absorbance at $620 \mathrm{~nm}$.

The sucrose content determination was performed using the following procedure:

Briefly, $0.1 \mathrm{~g}$ of each dried homogenized stem samples were placed in test tubes with $15 \mathrm{ml}, 80 \%$ ethanol was added, and then were water bathed at $80^{\circ} \mathrm{C}$ for $30 \mathrm{~min}$, then centrifuged at $5000 \mathrm{r} / \mathrm{min}$ for $15 \mathrm{~min}$, and the supernatant was transferred to a $50 \mathrm{ml}$ volumetric flask. The above procedures were repeated three times. The volumetric flask constant volume is $50 \mathrm{ml}$. Finally, we added $0.1 \%$ resorcinol and $10 \mathrm{~mol} / \mathrm{L}$ hydrochloride, and then were water bathed at $80^{\circ} \mathrm{C}$ for $30 \mathrm{~min}$ and then used the end product to measure the absorbance with a spectrophotometer at $480 \mathrm{~nm}$.

A lignin content determination was performed using the following procedure; in brief, $0.5 \mathrm{~g}$ of dried homogenized stem samples were placed in test tubes with $10 \mathrm{ml}$, and $72 \%$ sulphuric acid was added slowly with stirring. The samples were then left at room temperature for $3 \mathrm{~h}$ with frequent stirring and transferred completely to a flask. Water was added to reach a dilution with a $3 \%$ sulphuric acid concentration, and then the samples were boiled for $4 \mathrm{~h}$. The mixture was filtered through quantitative filter paper and washed with hot water until acid-free. The filter and lignin were dried at $105^{\circ} \mathrm{C}$ for $3 \mathrm{~h}$ until the weight was constant, then the weight was recorded. The lignin content was calculated using the following procedure: Lignin (\%) $=100 \mathrm{~W} / \mathrm{S}$; where $\mathrm{W}$ is the weight of the insoluble lignin $(\mathrm{g})$ and $\mathrm{S}$ is the weight of the dried stem sample (g). The cellulose content determination came before the following procedure. In brief, $0.1 \mathrm{~g}$ of dried homogenized stem samples were treated with $5 \mathrm{ml}$ of acetic/nitric reagent in a tube, and then they were placed in a water bath boiling for $30 \mathrm{~min}$, then centrifuged at $5000 \mathrm{r} / \mathrm{min}$ for $15 \mathrm{~min}$, and the supernatant was then discarded. We repeated the above steps three more times until the residues were white. After the above treatments, $5 \mathrm{ml}$ of $72 \%$ sulphuric acid was added to the tube and allowed to stand at room temperature for more than $12 \mathrm{~h}$, then transferred to a $50 \mathrm{ml}$ volumetric flask. The contents were washed several times with distilled water and transferred to a volumetric flask together to reach $50 \mathrm{ml}$. Finally, we added anthrone colorimetric reagents and then used the end product to measure the absorbance with a spectrophotometer at $620 \mathrm{~nm}$.

\section{RNA Extraction and Real-Time Quantitative PCR (qRT-PCR) Analysis}

The total RNA from the rice internode tissues was isolated using a Tiangen RNAprep Pure Plant kit (Beijing, China). After removing the genomic DNA contamination with DNase from the extracted RNA sample, the first-strand cDNA was synthesized by reverse transcriptase (Takara, Japan) according to the manufacturer's protocol. qRT-PCR was performed on the Roche 480 Real-time PCR system (Switzerland). Quantitative PCR analysis was performed using the first-strand cDNA as templates with the SYBR Premix Ex TaqTM (Tli RNaseH Plus) (Takara, Japan), according to the cycling profile described in the instructions with the following cycling profile: denaturation, $95^{\circ} \mathrm{C}$ for $30 \mathrm{~s}, 1$ cycle; PCR, $95^{\circ} \mathrm{C}$ for $5 \mathrm{~s}$ and $60^{\circ} \mathrm{C}$ for $30 \mathrm{~s}$, 40 cycles; melting, $95^{\circ} \mathrm{C}$ for $5 \mathrm{~s}\left(4.4^{\circ} \mathrm{C}\right.$ s/l cooling rate); and $60^{\circ} \mathrm{C}$ for $1 \mathrm{~min}\left(2.2^{\circ} \mathrm{C} \mathrm{s} / \mathrm{l}\right.$ cooling rate $), 95^{\circ} \mathrm{C}\left(0.11^{\circ} \mathrm{C} s / \mathrm{l}\right.$ cooling rate; continuous acquisition mode, 5 acquisitions per $\left.{ }^{\circ} \mathrm{C}\right), 1$ cycle. The $2^{-\Delta \Delta \mathrm{C}_{\mathrm{T}}}$ method was used to calculate the relative changes in expression levels (Livak and Schmittgen, 2001). The housekeeping $\beta$-actin gene was used as the internal reference. Each gene was tested using three replicates. The gene-specific primers are listed in Table $\mathbf{1}$.

\section{Statistical Analysis}

The figures were drawn with Origin 2015. The data are the means of three independent replicates. Statistically significant differences $\left({ }^{*}\right.$ represents $P<0.05,{ }^{* *}$ represents $P<0.01$ ) were determined by analyses of variance based on Student's $t$-tests.

\section{RESULTS}

\section{Effects of the Shading Treatment on the Yield and Yield Components}

Shading treatment had a significant effect on yield and yield components (Table 2). Under shading treatment, the 
TABLE 1 | List of primer sets used for quantitative real-time quantitative PCR (RT-PCR).

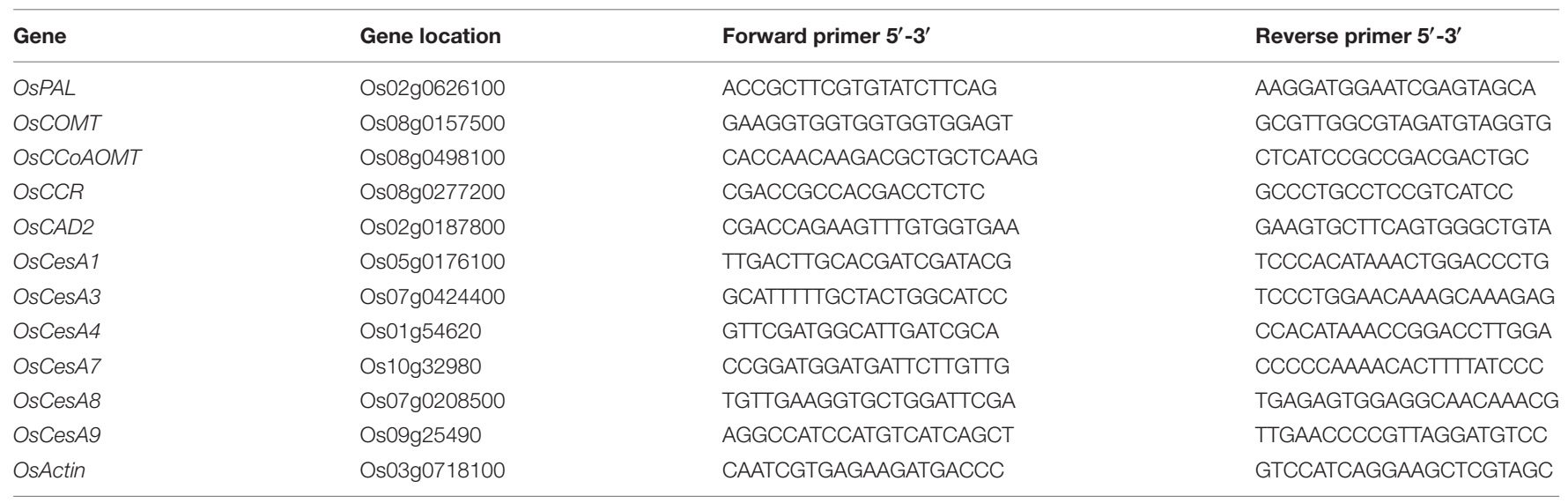

number of panicles per $\mathrm{m}^{2}$ increased, while the spikelets per panicles and spikelets per $\mathrm{m}^{2}$ decreased in both cultivars. The panicles of Wuyunjing23 increased by 25.9 and $26.3 \%$ in 2015 and 2016, respectively; and that of the W3668 increased by $19.9 \%$ in 2015 and $10.5 \%$ in 2016. By contrast, the spikelets per panicles were significantly reduced in Wuyunjing23, by $14.0 \%$ in 2015 and $36.2 \%$ in 2016, and that of the W3668 decreased by $31.7 \%$ in 2015 and $19.4 \%$ in 2016 . A similar reduction trend occurred in both cultivars for both years. Additionally, shading results in grain weight and yield reduction. Compared with the control, the grain weight decreased 4.4 and 2.1\% of Wuyunjing23 in 2015 and 2016, respectively; and that of W3668 by 6.9 and $4.6 \%$ in 2015 and 2016, respectively. A similar reduction trend was observed for the grain yield. However, the spikelets fertility had no significantly difference except Wuyunjing23 in 2015. The yield reduction under shading treatment was probably caused by the decreased spikelets per panicles, spikelets per $\mathrm{m}^{2}$ and grain weight.

\section{Effects of the Shading Treatment on the Culm Diameter, Culm Wall Thickness, Gravity Center Height and Plant Height}

The morphological traits were analyzed to evaluate the agronomic effects respond to shading. As shown in Table 3, shading treatment reduced culm diameter, culm wall thickness in both cultivars and years of the fourth internode from the top. While increased gravity center height and plant height in both cultivars over 2 years. These morphological characteristics showed similar trends under shading treatment.

\section{Effects of the Shading Treatment on the Breaking Strength, Bending Stress, and Bending Moment in the Whole Plant, and the Lodging Index}

The culm mechanical strengths (which were determined as the breaking strength) were determined at the fourth internodes

TABLE 2 | Effects of shading on grain yield and yield components of two japonica rice in 2015 and 2016.

\begin{tabular}{|c|c|c|c|c|c|c|}
\hline Treatment & Panicles $\left(\mathrm{m}^{2}\right)$ & Spikelets per panicles & Spikelets $\left(10^{3} / \mathrm{m}^{2}\right)$ & Spikelets fertility (\%) & grain weight (mg) & Yield (t/ha) \\
\hline \multicolumn{7}{|l|}{2015} \\
\hline \multicolumn{7}{|c|}{ Wuyunjing23 } \\
\hline Shading & $386.4^{* *}$ & 92.0 & 35.6 & $96.9^{*}$ & 30.6 & 10.6 \\
\hline \multicolumn{7}{|l|}{ W3668 } \\
\hline Control & 393.3 & $104.2^{* *}$ & 40.9 & 96.7 & $25.8^{* *}$ & $10.2^{* *}$ \\
\hline \multicolumn{7}{|l|}{2016} \\
\hline \multicolumn{7}{|c|}{ Wuyunjing23 } \\
\hline Control & 333.3 & $125.6^{* *}$ & $41.9^{* *}$ & 92.9 & $31.0^{* *}$ & $12.0^{*}$ \\
\hline Shading & $420.8^{* *}$ & 80.1 & 33.7 & 96.1 & 30.3 & 9.8 \\
\hline \multicolumn{7}{|l|}{ W3668 } \\
\hline Control & 478.3 & $88.3^{*}$ & 42.3 & 93.3 & $23.5^{* *}$ & 9.3 \\
\hline
\end{tabular}

Asterisks (*) represent significant differences relative to the Control $\left({ }^{*} P<0.05\right.$; $\left.{ }^{* *} P<0.01\right)$. 
from the top of the rice plants, where lodging occurred most easily. Both Wuyunjing23 and W3668 experienced an increased lodging index under shading treatment in both years. The lodging index of Wuyunjing 23 increased by $38.0 \%$ in 2015 and $4.5 \%$ in 2016, and the lodging index of W3668 increased by $22.9 \%$ in 2015 and $32.6 \%$ in 2016. By contrast, the breaking strength was significantly reduced in Wuyunjing 23 , by $26.7 \%$ in 2015 and $21.2 \%$ in 2016 , and that of the W3668 decreased by $32.6 \%$ in 2015 and $27.4 \%$ in 2016. A similar trend in the shading effects on the bending stress was observed in both cultivars and both

TABLE 3 | Effect of shading on culm diameter and culm wall thickness of the fourth internode from the top, gravity center height and plant height in two japonica rice.

\begin{tabular}{|c|c|c|c|c|}
\hline Treatments & $\begin{array}{c}\text { Clum } \\
\text { diameter } \\
(\mathrm{mm})\end{array}$ & $\begin{array}{c}\text { Culm wall } \\
\text { thickness } \\
\text { (mm) }\end{array}$ & $\begin{array}{c}\text { Gravity center } \\
\text { height }(\mathbf{c m})\end{array}$ & $\begin{array}{l}\text { Plant height } \\
\text { (cm) }\end{array}$ \\
\hline \multicolumn{5}{|l|}{2015} \\
\hline \multicolumn{5}{|l|}{ Wuyunjing23 } \\
\hline Control & 4.36 & $0.90^{* *}$ & 43.51 & 94.79 \\
\hline Shading & 4.32 & 0.75 & $45.57^{* *}$ & $100.60^{* *}$ \\
\hline \multicolumn{5}{|l|}{ W3668 } \\
\hline Control & $3.79^{* *}$ & $0.70^{* *}$ & 45.34 & 97.01 \\
\hline Shading & 3.42 & 0.52 & 46.08 & $99.82^{* *}$ \\
\hline \multicolumn{5}{|l|}{2016} \\
\hline \multicolumn{5}{|l|}{ Wuyunjing23 } \\
\hline Control & $4.67^{* *}$ & $0.86^{* *}$ & 34.90 & 82.15 \\
\hline Shading & 4.41 & 0.74 & $38.43^{* *}$ & $85.50 *$ \\
\hline \multicolumn{5}{|l|}{ W3668 } \\
\hline Control & $3.89 *$ & $0.69 * *$ & 38.41 & 86.87 \\
\hline Shading & 3.74 & 0.57 & $40.86^{* *}$ & 89.87 \\
\hline
\end{tabular}

Asterisks (*)represent significant differences relative to the Control under shading treatment ( ${ }^{*} P<0.05$; ** $P<0.01$ ).

TABLE 4 | Effects of shading on breaking strength (M), bending stress (BS), bending moment by whole plant (WP) and lodging index (LI) of the fourth internode from the top in two japonica rice at 20 days after the heading stage.

\begin{tabular}{|c|c|c|c|c|}
\hline Treatments & $M(g \mathrm{~cm})$ & BS (g cm) & WP $(\mathrm{g} \mathrm{cm})$ & 니 (\%) \\
\hline \multicolumn{5}{|l|}{2015} \\
\hline \multicolumn{5}{|c|}{ Wuyunjing23 } \\
\hline Control & $2780.7^{* *}$ & $4171.5^{* *}$ & 1741.2 & 62.8 \\
\hline Shading & 2041.0 & 3411.8 & 1765.5 & $86.6^{* *}$ \\
\hline \multicolumn{5}{|l|}{ W3668 } \\
\hline Control & $1557.3^{* *}$ & 3688.9 & $1298.7^{* *}$ & 83.5 \\
\hline Shading & 1049.0 & 3601.2 & 1077.0 & $102.7^{* *}$ \\
\hline \multicolumn{5}{|l|}{2016} \\
\hline \multicolumn{5}{|c|}{ Wuyunjing23 } \\
\hline Control & $2679.9^{* *}$ & $3389.2^{* *}$ & $1179.7^{* *}$ & 44.0 \\
\hline Shading & 2111.4 & 3328.1 & 972.0 & 46.1 \\
\hline \multicolumn{5}{|l|}{ W3668 } \\
\hline Control & $1289.0^{* *}$ & 2920.9 & 783.9 & 60.8 \\
\hline Shading & 936.0 & 2558.3 & 775.1 & $82.8^{* *}$ \\
\hline
\end{tabular}

years. Shading treatment resulted in a significant reduction in the bending moment by the whole plant in W3668 in 2015 and Wuyunjing23 in 2016. Wuyunjing23 had higher breaking strength and bending stress, leading to a lower lodging index (Table 4).

\section{Effect of the Shading Treatment on Microstructure Characteristics}

Electron microscope images of transverse sections were scanned to observe the stem development. Compared with W3668, the sclerenchyma cells layers of Wuyunjing23 were thicker (Figure 1). Shading altered the minute structures, such as the inner sclerenchyma cell layer, leading to the presence of more hollow cells in parenchyma cells tissues and thin sclerenchyma cell tissues for both cultivars (Figures 1B,D). The results showed that when shading from the jointing to the heading stages, it altered the stem cell wall microstructure characteristics and the component concentration.

\section{Effect of the Shading Treatment on Lignin and Cellulose Arrangement and Localization}

The structural carbohydrates lignin and cellulose contributed to the culm mechanical strength. As shown in Figure 2, the red-pink phloroglucinol staining of shading treatment samples was lighter than that of the Control for both cultivars (Figures 2B,D). These findings indicated that shading decreased the amount of lignin deposition in the sclerenchyma cells and around the vascular bundle sheath, as led by relatively poorer lignifications and more poorly developed secondary cell walls.

Similarly, the cellulose fluorescence intensity in the parenchyma cells of the shading treatment samples was weaker than that of the Control for both cultivars (Figures 3B,D). This finding was indicated by the lower densities of cellulose distribution under shading treatment.

\section{Effects of Shading Treatment on the Non-structural Carbohydrate, Sucrose, Lignin, and Cellulose Contents}

Furthermore, the contents of non-structural carbohydrates, sucrose, lignin, and cellulose in the fourth internodes from the top were investigated to distinguish among the changes in the cell wall component concentrations under shading in a quantitative manner. Shading was shown to decrease the non-structural carbohydrate content in both Wuyunjing23 and W3668 in both years (Figure 4). There were decreases of 73.3, 70.9, 62.5, and $63.8 \%$; and $90.8,88.1,53.2$, and $40.7 \%$ for Wuyunjing 23 in 2015 and 2016 (Figures 4A,C), respectively; a similar reduction was observed in non-structural carbohydrate contents, with differences of 55.5, 34.0, 60.4, and 40.6\%; and 78.3, 90.4, 47.5, and 3.3\% for W3668 in 2015 and 2016 (Figures 4B,D).

The sucrose content was observed reduced and then increased from 20 days before heading to 20 days after heading under shading treatment (Figure 5). As compared to control, the sucrose content decreased at 20, 10 days before heading, and was observed an increasing trend at 20 days after heading. These 

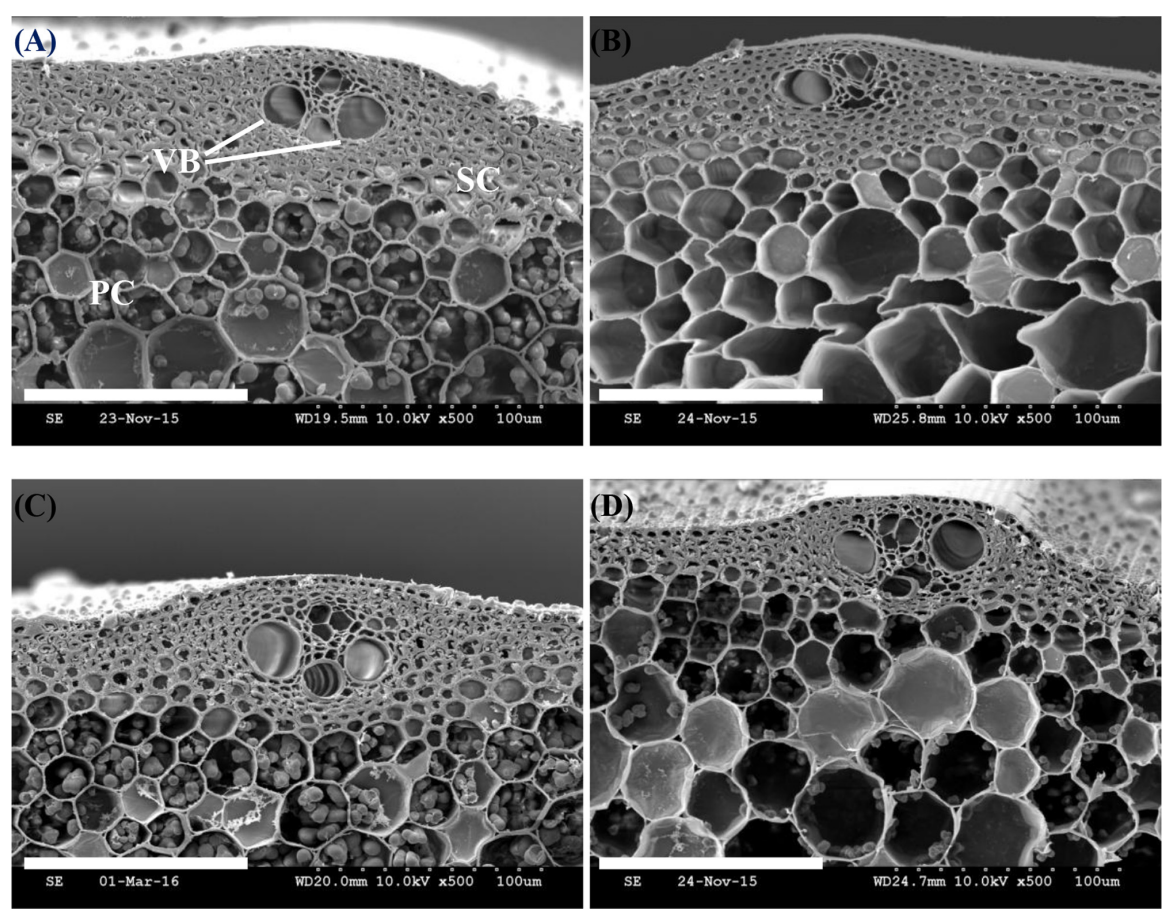

FIGURE 1 | Effect of shading on scanning electron micrographs (SEM) in the microstructures of sclerenchyma cells and vascular bundle (VB) in the transverse section of the fourth internode from the top. PC, parenchyma cells; SC, sclerenchyma cells. (A,B) Cross-section of culm tissue in Wuyunjing23 under the Control and Shading treatment, respectively; (C,D) Cross-section of the culm tissue in W3668 under the Control and Shading treatment, respectively. Bar $=100 \mu \mathrm{m}$.
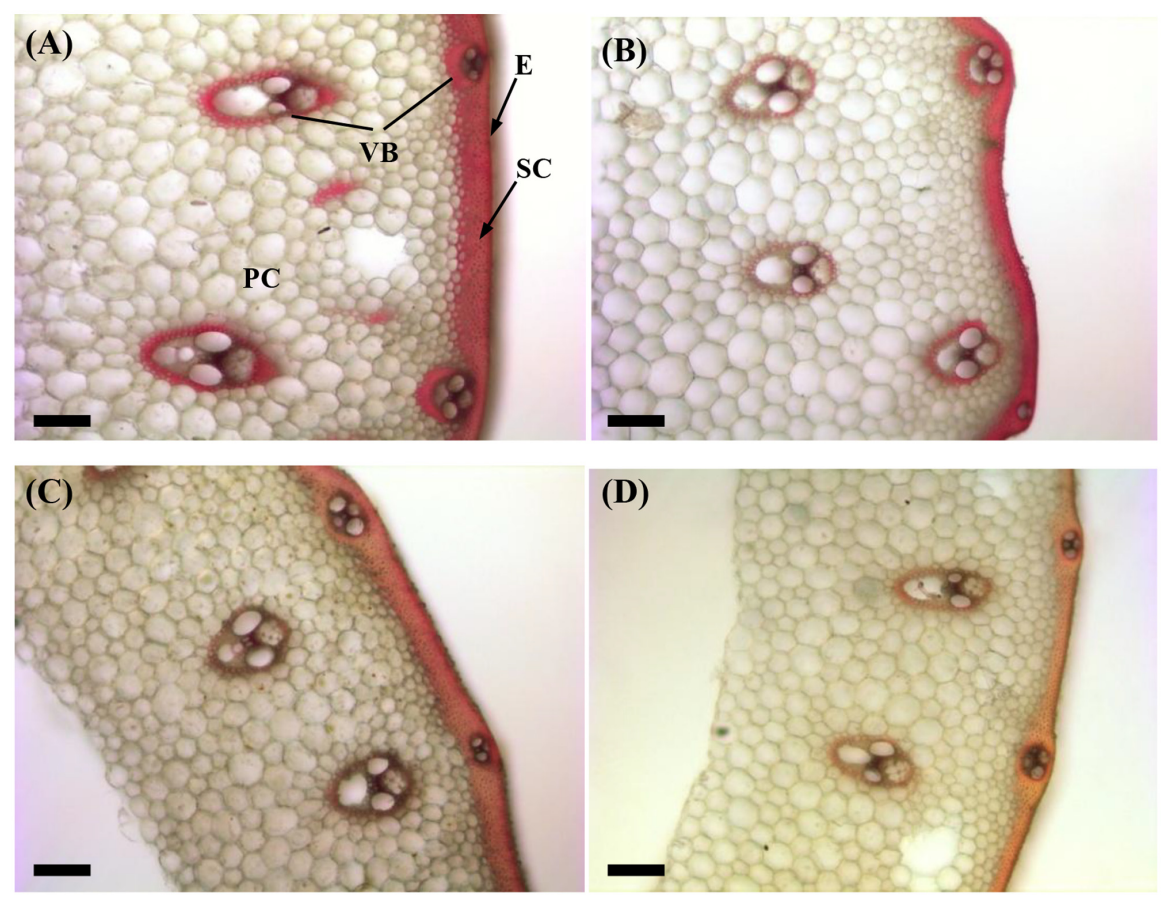

FIGURE 2 Effect of shading on Wiesner staining of the transverse internode section of the fourth internode from the top of Wuyunjing23 and W3668 plants. (A,B) Phloroglucinol staining of Wuyunjing23 under Control and Shading, respectively; (C,D) phloroglucinol staining of W3668 under Control and Shading, respectively. Bars $=100 \mu \mathrm{m}$. E, epidermis; PC, parenchyma cells; SC, sclerenchyma cells; VB, vascular bundle. 

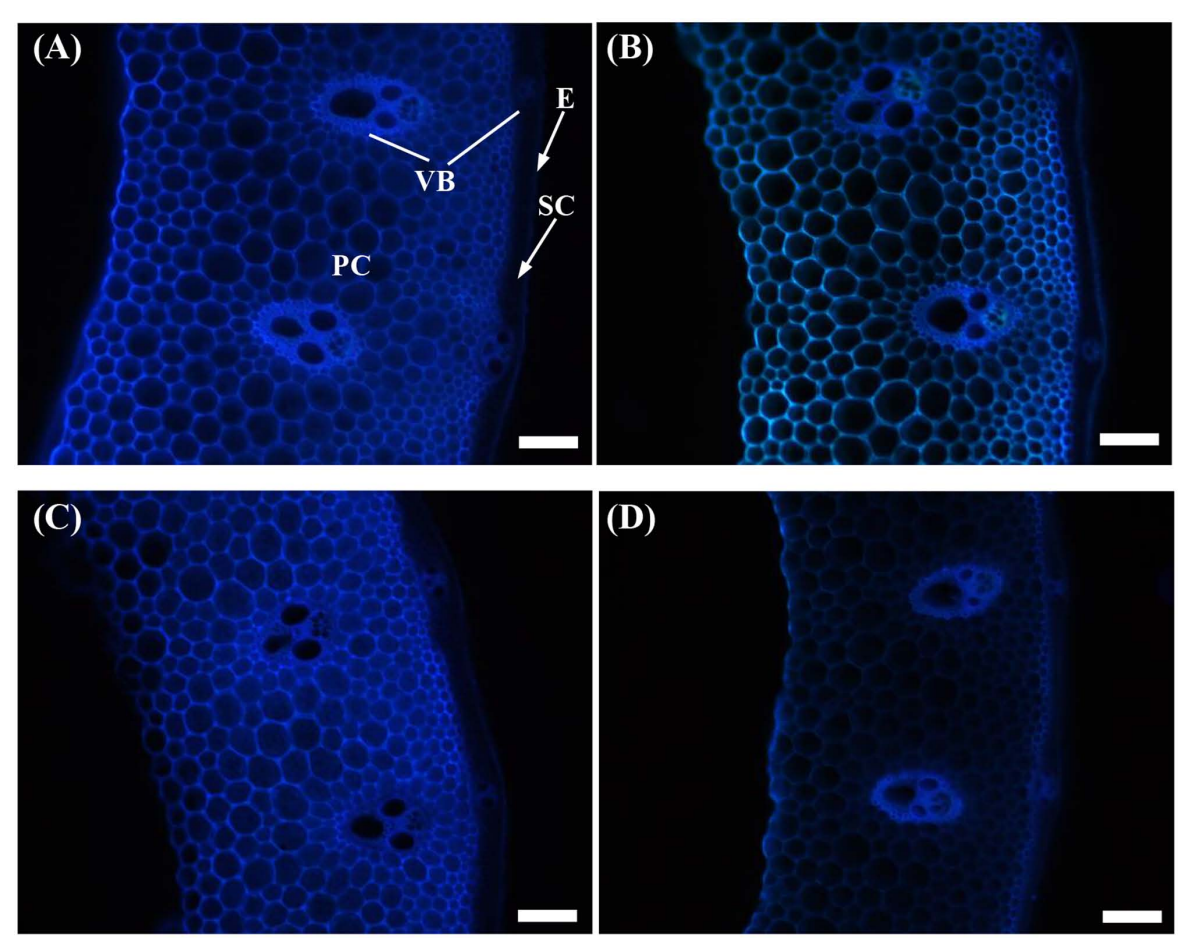

FIGURE 3 | Effect of shading on calcofluor staining of the transverse internode section of the fourth internode from the top of Wuyunjing23 and W3668 plants. (A,B) Calcofluor staining of Wuyunjing23 under Control and Shading, respectively; (C,D) calcofluor staining of W3668 under Control and Shading, respectively. E, epidermis; PC, parenchyma cells; SC, sclerenchyma cells; VB, vascular bundle. Bars $=100 \mu \mathrm{m}$.

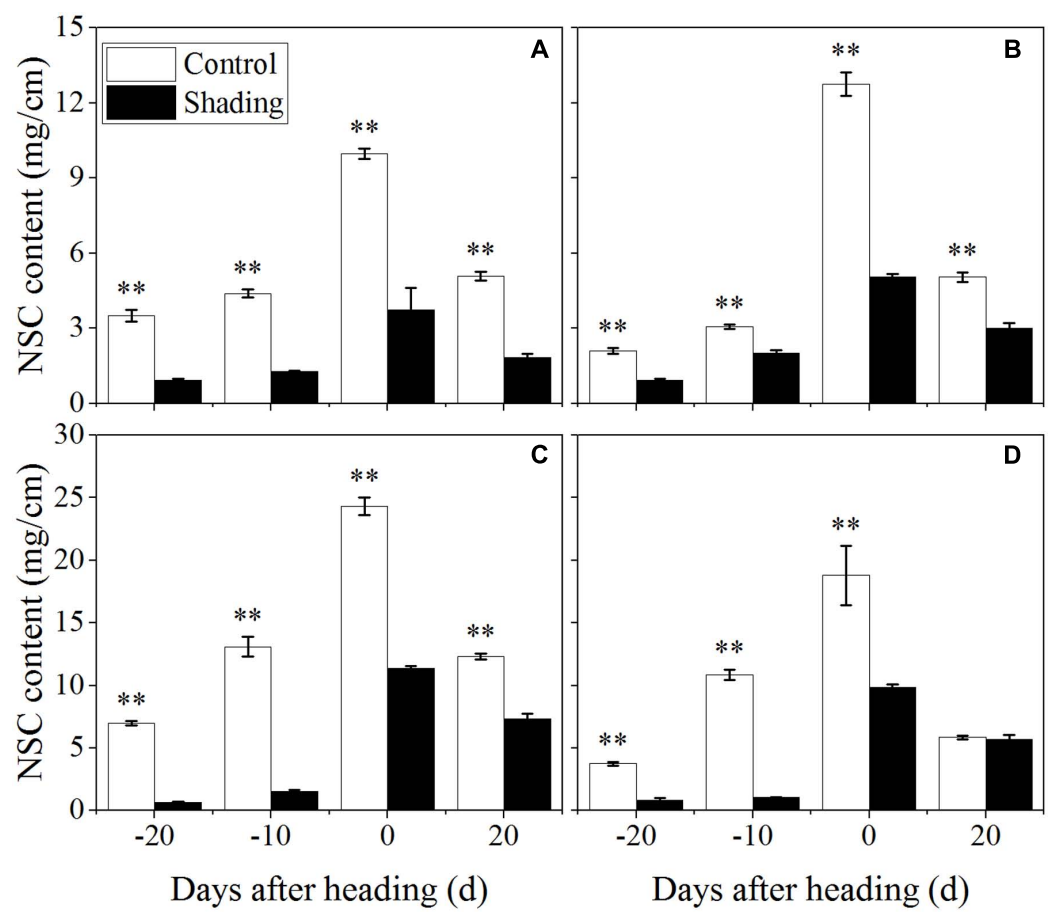

FIGURE 4 | Effect of shading on NSC (non-structural carbohydrate) content in the culm tissue of the fourth internode from the top from 20 days before heading to 20 days after heading in Wuyunjing23 (A,C) and W3668 (B,D). (A,B: 2015; C,D: 2016) Asterisks $\left(^{*}\right)$ represent significant differences relative to the Control under different stages of culm growth $(* P<0.05 ; * * P<0.01)$. 


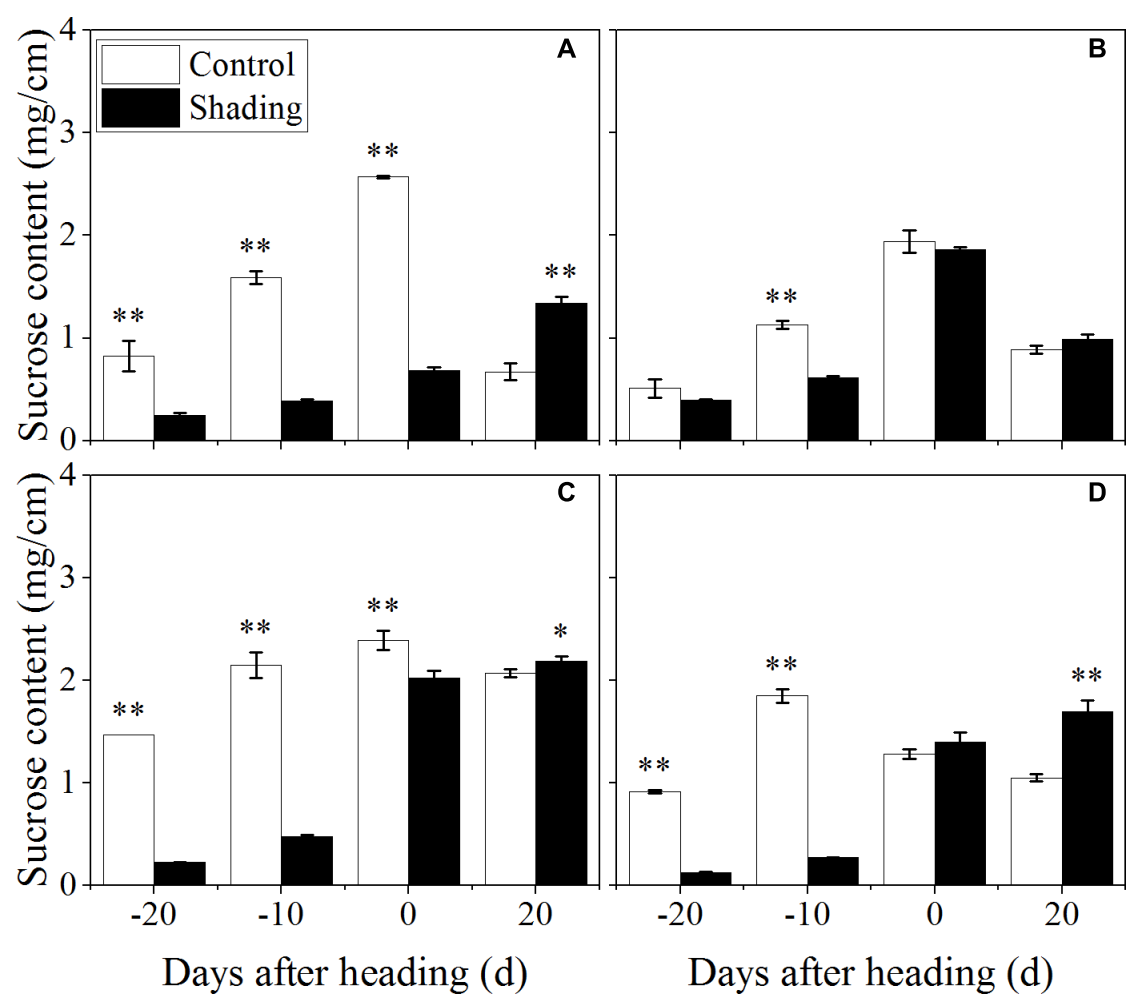

FIGURE 5 | Effect of shading on sucrose content in the culm tissue of the fourth internode from the top from 20 days before heading to 20 days after heading in Wuyunjing23 (A,C) and W3668 (B,D). (A,B: 2015; C,D: 2016) Asterisks $\left(^{*}\right)$ represent significant differences relative to the Control under different stages of culm growth $\left({ }^{*} P<0.05 ;{ }^{* *} P<0.01\right)$.

data suggesting that shading decreased the sucrose content at elongation stage, while increased sucrose content at 20 days after heading.

The shading treatment also decreased the lignin content in both Wuyunjing23 and W3668 in both years (Figure 6). There were decreases of 69.7, 54.1, 56.4, and 39.8\%; and 56.7, 39.3, 17.1, and $19.4 \%$ for Wuyunjing23 in 2015 and 2016 (Figures 6A,C), respectively; a similar reduction was observed in the lignin content with changes of $60.2,30.3,29.4$, and $24.4 \%$; and 66.8 , 42.1, 2.4, and 27.7\% for W3668 in 2015 and 2016 (Figures 6B,D). The cellulose content under shading was decreased significantly in Wuyunjing23, and it decreased by $36.6,27.8,20.3$, and $23.4 \%$; and $63.6,59.9,23.5$, and $25.6 \%$ in 2015 and 2016, respectively (Figures 7A,C). Similarly, the cellulose content of W3668 was decreased under shading treatment, by $20.5,4.5,23.3$, and $15.2 \%$; and 39.2, 52.3, 3.8, and 21.1\%, respectively (Figures 7B,D).

The non-structural carbohydrate, lignin, and cellulose concentrations responded to shading treatment in a consistent fashion in the two cultivars. These concentrations were consistent with the lignin and cellulose staining (Figures 2, 3) and were in accordance with the microstructure characteristics (Figure 1). However, the sucrose content was observed a reduction and then increment trend. These data suggesting that the sucrose content was strongly regulated by shading treatment. These results also indicated that shading decreased the lignin and cellulose content and thus affected the culm mechanical strength.

\section{Effect of Shading Treatment on Lignin and Cellulose Biosynthesis Gene Expression}

The expression of the genes known to be involved in lignin and cellulose synthesis in culms was investigated with qRT-PCR to characterize the role of shading in the process. The expression levels of OsPAL (phenylalanine ammonia-lyase), OsCOMT (Caffeic acid 3-O-methyltransferase), OsCCoAOMT (Caffeoyl coenzyme A 3-O-methyltransferase), OsCCR (Cinnamoyl-CoA reductase), OsCAD2 (cinnamyl alcohol dehydrogenase), which are involved in the phenylpropanoid pathway for lignin biosynthesis, were analyzed (Figure 8). OsPAL was found to have the highest expression levels at 10 and 15 days before heading in Wuyunjing23 and W3668, respectively. OsCOMT, OsCCoAOMT, OsCCR, and OsCAD2 displayed the highest expression levels at 15 days before heading in both Wuyunjing23 and W3668, while OsCCoAOMT was highest at 20 days before heading in W3668. Compared with the shading treatment, the expression levels of OsPAL, OsCOMT, OsCCoAOMT, OsCCR, and OsCAD2 were down-regulated significantly at most sampling times before the heading stage. These results support the conclusion that shading largely reduces lignin biosynthesis in culm tissue before the heading stage.

To clarify the effects of shading on cellulose biosynthesis in cell walls, the expression levels of OsCesA1 (Cellulose synthases), 


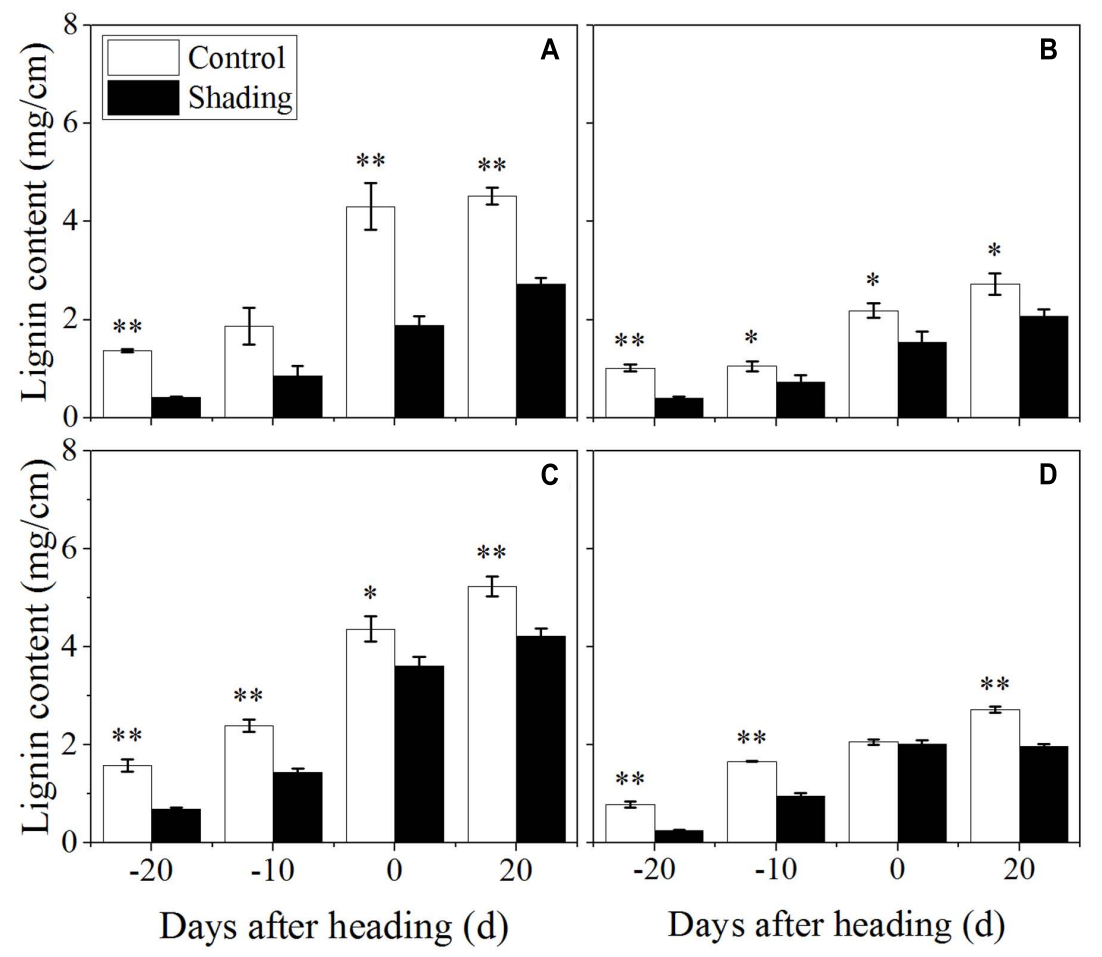

FIGURE 6 | Effect of shading on lignin content in the culm tissue of the fourth internode from the top from 20 days before heading to 20 days after heading in Wuyunjing23 (A,C) and W3668 (B,D). (A,B: 2015; C,D: 2016) Asterisks $\left({ }^{*}\right)$ represent significant differences relative to the Control under different stages of culm growth $\left({ }^{*} P<0.05 ;{ }^{*} P<0.01\right)$

OsCesA3 and OsCesA8 (Wang et al., 2010) were studied, and they were primarily expressed in the primary cell wall. OsCesA4, OsCesA7, and OsCesA9 (Kotake et al., 2011) were primarily expressed in secondary cell walls. As shown in Figure 9, OsCesA1, OsCesA3, and OsCesA8 were up-regulated first and then down-regulated in both cultivars under shading treatment. Compared to the control, OsCesA1 showed a lower expression level at 20 and 10 days before heading for Wuyunjing23, and at 25,15 , and 10 days before heading for W3668 under shading treatment, respectively. OsCesA3 had a lower expression level at 25,20, and 15 days; and at 25, 15, 10, and 5 days before heading in Wuyunjing 23 and W3668 compared to the control, respectively. OsCesA8 displayed a lower expression level at 25, 20, 15 , and 10 days; and at 25,20,15, and 10 days before heading in Wuyunjing23 and W3668 compared to the control, respectively. Therefore, the cellulose biosynthetic pathway-related genes in the primary cell wall were strongly down-regulated before the heading stage. As shown in Figure 10, except at 15 days before heading, OsCesA4, OsCesA7, and OsCesA9 were down-regulated, while at the other stage, OsCesA4, OsCesA7, and OsCesA9 were up-regulated.

\section{DISCUSSION}

Solar radiation is an important environmental factor in plant growth and development. Shading leading to lower PAR was recognized as a plant stress. Several investigations have reported that shading on plant growth and yield in several crops (Beed et al., 2007; Liu and Tollenaar, 2009; Mo et al., 2015). Here we have found that shading had a significant effect on grain yield and yield components. Shading resulted in reduction of spikelets per panicles, spikelets per square meters, grain weight, and then resulted in grain yield reduction in the two cultivars over 2 years, which consist with previous studies in rice (Mo et al., 2015). These results demonstrate that yield and yield components were affected by shading treatment.

Previous studies have shown that shading leads to slender stems in rice (Liu et al., 2016), soybeans (Liu W. et al., 2015), and Arabidopsis (Yu et al., 2015) and increased lodging rates in maize (Xue et al., 2016) and wheat (Sparkes and King, 2008). Shading treatments decreased the dry weight per unit length and the rind penetration strength, suggesting that shading led to lower stem strength and increased lodging rates (Xue et al., 2016). In this study, shading during elongation up to the heading stage significantly reduced the stem-breaking strength and resulted in an increased lodging index. This result was related closely to the results of previous investigations in which shading decreased the stem mechanical strength and increased the lodging rate.

Plant height and gravity center height were important morphologic traits related to lodging (Chandler, 1969; Kashiwagi et al., 2008). In the present study, shading increased plant height, gravity center height of japonica rice stems thereby 


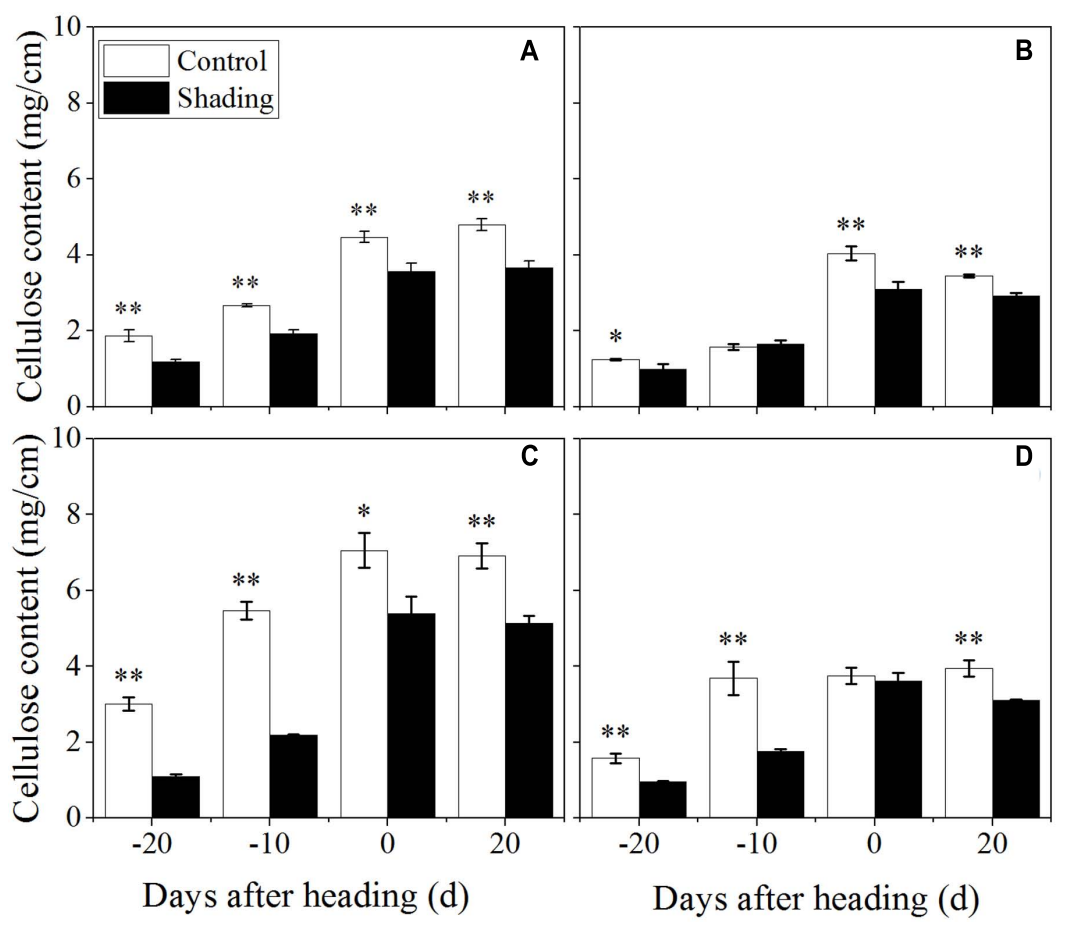

FIGURE 7 | Effect of shading on cellulose content in the culm tissue of the fourth internode from the top from 20 days before heading to 20 days after heading in Wuyunjing23 (A,C) and W3668 (B,D).(A,B: 2015; C,D:2016) Asterisks $\left(^{*}\right)$ represent significant differences relative to the Control under different stages of culm growth $\left(* P<0.05 ;{ }^{*} P<0.01\right)$.

increasing the risk of lodging. In addition, culm diameter and culm wall thickness were also primary factors related to lodging (Zuber et al., 1999; Islam et al., 2007). In this study, shading decreased culm diameter and culm wall thickness of the basal second internode under shading treatment, which was consistent of previous reports (Liu et al., 2016). Thus, the basal second internode of shading treated stems were more slender leading to lower mechanical strength, which increased the lodging index (Table 4).

The thicknesses of mechanical tissue layers and vascular bundle sheath cells are the primary sources of mechanical strength, and they are important for crop lodging resistance at the anatomical level (Zhang et al., 2016b). In cereal plants, sclerenchyma cell tissues and vascular bundle tissues provide mechanical support for plants (Li et al., 2009; Kong et al., 2013). In the present study, shading decreased the layers of sclerenchyma cells for the mechanical tissues and vascular bundle tissues (Figure 1), and the variation trends of the two varieties were consistent. Furthermore, shading also led to many hollow tissues in parenchymal cell tissues. The results showed that shading decreased the thickness of mechanical tissues and resulted in decreased mechanical strength.

The stem mechanical strength is primarily dependent on the cell wall components (Kashiwagi et al., 2008) lignin and cellulose, which are the primary biochemical components that are closely associated with stem mechanical strength and that are positively associated with lodging resistance (Li et al., 2013; Peng et al., 2014; Zhang et al., 2014). In this study, we noted that shading decreased the non-structural carbohydrates (Figure 4), lignin (Figure 6), cellulose accumulation (Figure 7), and sucrose content before heading (Figure 5). Combined with histochemical staining, the decreased lignin accumulation is primarily reflected in the sclerenchyma tissue cells (Figure 2). The decreased cellulose accumulation is primarily reflected in the parenchyma tissues (Figure 3), and the non-structural carbohydrates that filled in the parenchyma tissues were decreased. Lignin is known as the material that thickens secondary cell walls, and it provides mechanical support for plants; cellulose acts as a net support for plants, and non-structural carbohydrates fill the parenchyma tissues to provide stem plumpness. In addition, sucrose as the main photosynthetic products transported to other non-photosynthetic tissues (Rolland et al., 2001), sucrose not only provide substrate for cellulose synthesis (Amor et al., 1995), but also provide carbon source for lignin biosynthesis (Rogers et al., 2005). In the present study, shading declined sucrose accumulation before heading thereby. However, the sucrose concentration was higher at 20 days after heading; therefore, a lot of sucrose could not be used in cellulose or lignin biosynthesis, leading to the decrease of cellulose and lignin concentration. Thereby reduced carbon reduced carbon source for cellulose and lignin biosynthesis. Thus, the results showed that shading decreased the stem plumpness and stem mechanical strength, and thus it increased the lodging index.

Moreover, lignin or cellulose biosynthesis gene mutations caused lignin or cellulose accumulation and decreased mechanical strength. OsCesA4, OsCesA7, and OsCesA9 


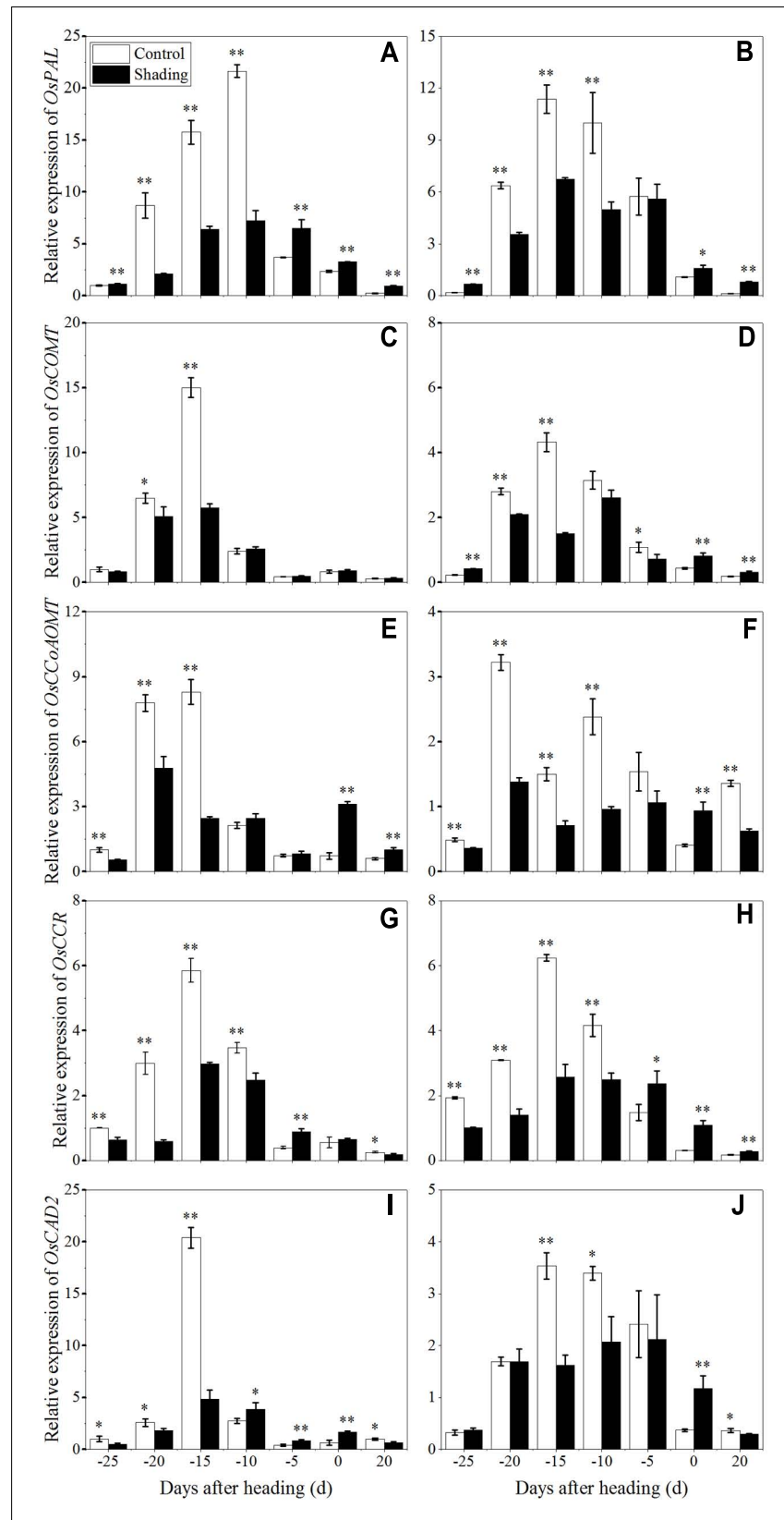

FIGURE 8 | Effects of shading on the expression of OSPAL in Wuyunjing23 (A) and W3668 (B), the expression of OsCOMT in Wuyunjing23 (C) and W3668 (D), the expression of OsCCOAOMT in Wuyunjing23 (E) and W3668 (F), the expression of OsCCR in Wuyunjing23 (G) and W3668 (H) and the expression of OsCAD2 in Wuyunjing23 (I) and W3668 (J) in from 25 days before heading to 20 days after heading. Total RNA was isolated from culm tissues of the fourth internode from the top of the plant. $\beta$-actin was used as a loading control, and the value obtained from the Control treatment at 25 days before heading was arbitrarily set as 1.0. Real-time PCR was performed in triplicate, and the mean values with SD are shown. Asterisks represent significant differences relative to the Control treatment under different stages of culm growth ( $\left.{ }^{*} P<0.05 ;{ }^{* *} P<0.01\right)$.

encode secondary cell wall cellulose biosynthesis (Kotake et al., 2011), and its related mutation decreased the cellulose concentration and mechanical strength. OsCesA1, OsCesA3, and OsCesA8 encode the components of primary cell wall cellulose biosynthesis (Tanaka et al., 2003; Wang et al., 2010). To gain insights into the physiological and molecular basis for the regulation of cellulose and lignin biosynthesis in rice tissues under shading, we detected the spatiotemporal expression pattern of selected cellulose and lignin biosynthesis genes. Previous studies showed that mutations in the rice cellulose biosynthesis genes resulted in loose cell walls and decreased mechanical strength (Tanaka et al., 2003). In addition, the rice brittle culms $B C 1, B C 3, B C 5, B C 10, B C 12, B C 14$, and $B C 15$ showed lower cellulose and lower mechanical strength (Aohara et al., 2009; Zhou et al., 2009; Hirano et al., 2010; Zhang et al., 2010, 2011; Wu et al., 2012). Cellulose is synthesized with sucrose as the substrate (Amor et al., 1995), while the sucrose metabolism was sensitive to shading. Shading decreased the sucrose and cellulose contents (Chen et al., 2014), suggesting that shading led to lower cellulose accumulation in cotton. However, these investigations did not provide explanations of the mechanisms underlying those results in rice for shading between structural carbohydrates and lodging resistance. OsCesA1, OsCesA3, and OsCesA8; and OsCesA4, OsCesA7, and OsCesA9 genes are the major genes that are responsible for cellulose biosynthesis in the primary cell walls (Tanaka et al., 2003; Wang et al., 2010; Li et al., 2014) and secondary cell walls (Tanaka et al., 2003; Wang et al., 2010; Kotake et al., 2011; Li et al., 2014) of rice stems, respectively. Primary cell walls experience inward thickening formed by secondary cell walls. Cellulose accumulation within plants may mostly be regulated by cellulose biosynthesis genes. In the present research, the initial down-regulation of OsCesA1, OsCesA3, and OsCesA 8 was probably caused by shading, and the next upregulation of cellulose biosynthesis genes was a self-regulating phenomenon. The reduced cellulose content (Figure 7) was consistent with the less strong calcofluor staining for cellulose (Figure 3). Similar findings have been reported in cotton (Chen et al., 2014). Herein, we also observed the compensatory regulation of cellulose biosynthesis genes. Shading decreased the transcript levels of primary cell walls while increasing the transcript levels of genes encoding cellulose in secondary cell walls, but it decreased the concentration of cellulose. In fact, the compensatory regulation of cellulose biosynthesis is firmly established as a mechanism for adapting to adverse environment conditions such as shading. The reduction of cellulose accumulation under shading in parenchyma cells is primarily due to the down-regulation of OsCesA1, OsCesA3, and OsCesA8 expression (Figure 9) before heading, and it resulted in reductions in mechanical strength to some extent. This research also found that cellulose accumulation in mechanical tissues and the periphery of vascular bundles exhibited little variation under shading compared to the control, which was primarily due to the up-regulation of OsCesA4, OsCesA7, and OsCesA9 expression (Figure 10) before heading.

Moreover, Lignin can enhance stem mechanical strength by incorporating into cell walls. As previous reported, the expression of PAL, COMT, CCOAOMT, CCR and CAD and genes, which are involved in lignin biosynthesis, was associated with culm rigidity 

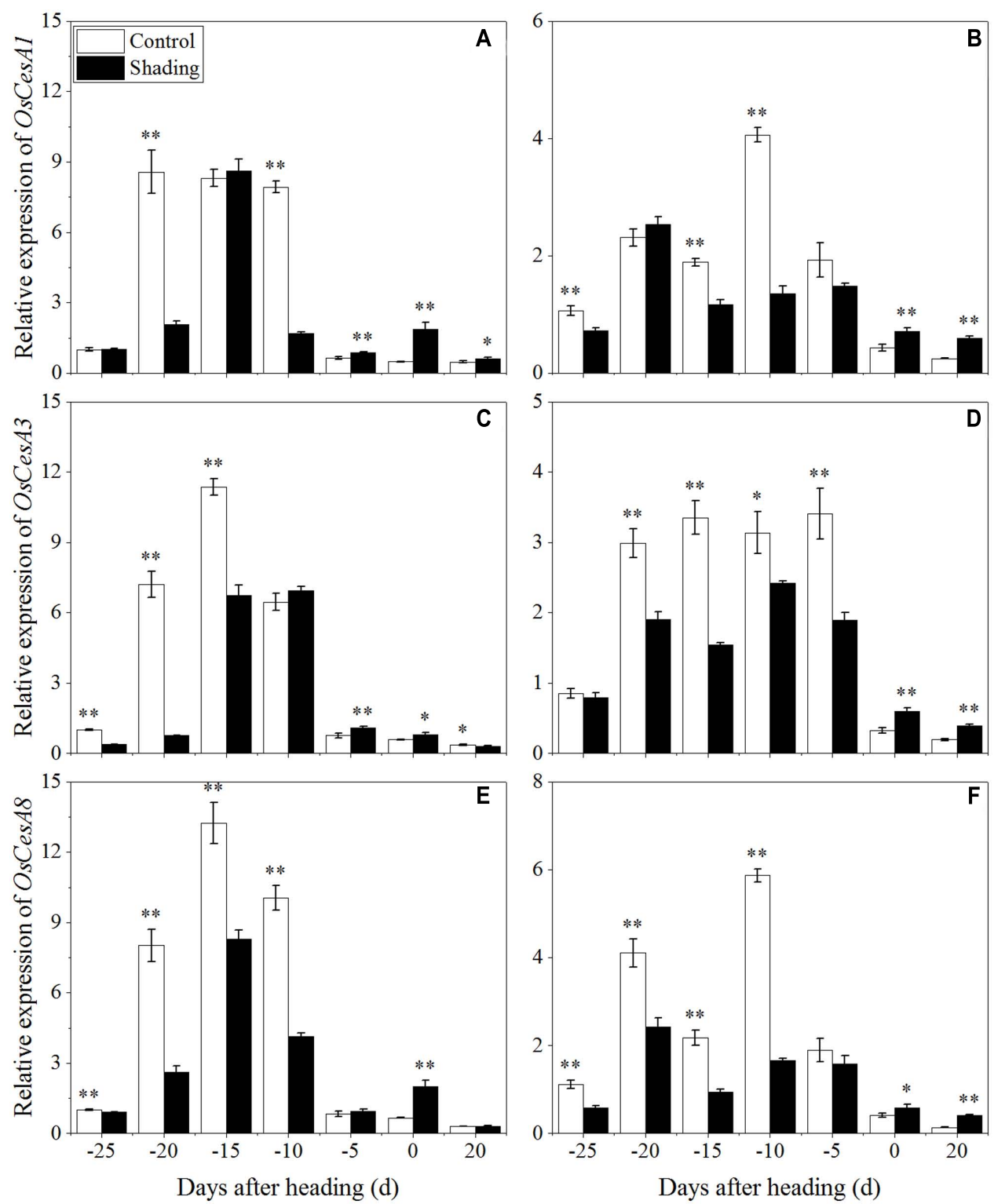

FIGURE 9 | Effects of shading on the expression of OsCesA1 in Wuyunjing23 (A) and W3668 (B), the expression of OsCesA3 in Wuyunjing23 (C) and W3668 (D), and the expression of OsCesA8 in Wuyunjing23 (E) and W3668 (F) from 25 days before heading to 20 days after heading. Total RNA was isolated from culm tissues of the fourth internode from the top of the plant. $\beta$-actin was used as a loading control, and the value obtained from the Control treatment at 25 days before heading was arbitrarily set as 1.0. Real-time PCR was performed in triplicate, and the mean values with SD are shown. Asterisks represent significant differences relative to the Control treatment under different stages of culm growth $\left({ }^{*} P<0.05\right.$; $\left.{ }^{* *} P<0.01\right)$.

and lodging resistance (Ma, 2009, 2010; Ma and Luo, 2015). The functions of lignin in maintaining stem mechanical strength and lodging resistance were further reported in buckwheat (Wang C. et al., 2015), rice (Li et al., 2009; Zhang et al., 2014), and sorghum (Sattler et al., 2009). In addition, lignin is a classic phenolic compounds, and it was sensitive to light (Koyama et al., 2012). In tea, shading influenced the phenylpropanoid biosynthesis pathway, implying that light was an important environment factor that affected phenylpropanoid metabolism, and lignin may be the primary phenylpropanoid metabolic product of light induction (Wang et al., 2012a,b). This finding implied that lignin biosynthesis is affected by light environments (Koyama et al., 2012). However, there is no direct proof to demonstrate that light influenced lignin accumulation in rice stems. In the present study, we found that shading decreased the lignin content in sclerenchyma cells and the vascular bundles of the fourth internodes (Figure 2). The down-regulation of OsPAL, OsCOMT, OsCCoAOMT, OsCCR, and OsCAD2 genes (Figure 8) was observed at 20-10 days before heading (the early or mid-period of jointing stage) under shading, while 

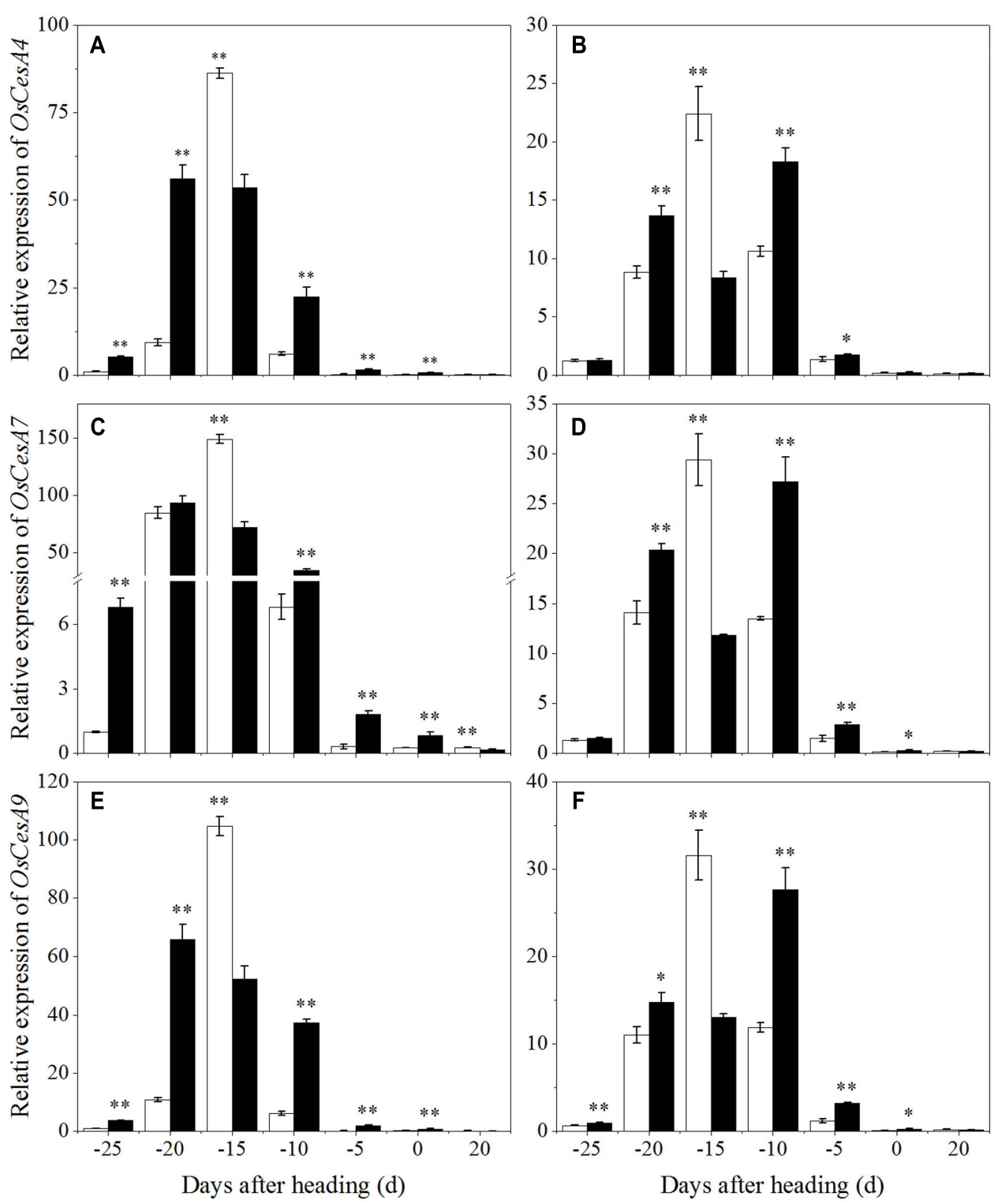

FIGURE 10 | Effects of shading on the expression of OsCesA4 in Wuyunjing23 (A) and W3668 (B), the expression of OsCesA7 in Wuyunjing23 (C) and W3668 (D), and the expression of OsCesA9 in Wuyunjing23 (E) and W3668 (F) from 25 days before heading to 20 days after heading. Total RNA was isolated from culm tissues of the fourth internode from the top of the plant. $\beta$-actin was used as a loading control, and the value obtained from the Control treatment at 25 days before heading was arbitrarily set as 1.0. Real-time PCR was performed in triplicate, and the mean values with SD are shown. Asterisks represent significant differences relative to the Control treatment under different stages of culm growth $(* P<0.05$; ** $P<0.01)$.

this stage was vital stage of lignin accumulation and cell wall thickening. These findings implied that shading restrained the lignin biosynthesis gene expression at this stage, which may be a lignin biosynthesis response to shading, and the restraining trends in gene expression under shading were consistent with the decreased lignin content (Figure 6) and the phloroglucinol staining of lignin (Figure 2). However, the later period, lignin biosynthesis gene expression was observed to be up-regulated under shading, it may be a self-regulating phenomenon or a shade-avoidance syndrome to compensate for the shading condition. These findings indicated that shading down-regulated the lignin biosynthesis genes in the early jointing stages, resulting in lignin accumulation deficits in mechanical tissues and vascular bundles, leading to an increased lodging index and decreased lodging resistance.

In summary, shading treatment decreased sucrose concentration and resulted in decreased carbon supply for cellulose and lignin biosynthesis, thus affected the expression of the key genes involved in cellulose and lignin biosynthesis. The alteration of gene expression restrain caused a decrease in the cellulose and lignin contents. Therefore, we believe that the above mentioned results are valuable for providing underlying 
mechanism of the decreased stem mechanical strength under shading condition.

\section{AUTHOR CONTRIBUTIONS}

Conceived and designed the experiments: LW, GL, and YD. Performed the experiments: LW, WZ, and JZ. Collected samples: LW, WZ, JZ, FW, and EC Analyzed the data: LW, WZ, JZ, and GL Provided good advice: ZL, ST, CD, LC, and SW. Drafted the manuscript: LW. Revised the manuscript and gave final approval of the version to be published: LW and GL.

\section{REFERENCES}

Amor, Y., Haigler, C. H., Johnson, S., Wainscott, M., and Delmer, D. P. (1995). A membrane-associated form of sucrose synthase and its potential role in synthesis of cellulose and callose in plants. Proc. Natl. Acad. Sci. U.S.A. 92, 9353-9357. doi: 10.1073/pnas.92.20.9353

Aohara, T., Kotake, T., Kaneko, Y., Takatsuji, H., Tsumuraya, Y., and Kawasaki, S. (2009). Rice BRITTLE CULM 5 (BRITTLE NODE) is involved in secondary cell wall formation in the sclerenchyma tissue of nodes. Plant Cell Physiol. 50, 1886-1897. doi: 10.1093/pcp/pcp133

Beed, F., Paveley, N., and Sylvester-Bradley, R. (2007). Predictability of wheat growth and yield in light-limited conditions. J. Agric. Sci. 145, 63-79. doi: 10.1017/S0021859606006678

Chandler, R. F. Jr. (1969). Plant Morphology and Stand Geometry in Relation to Nitrogen. Lincoln, NE: University of Nebraska, Lincoln, 1-27.

Chen, J., Lv, F., Liu, J., Ma, Y., Wang, Y., Chen, B., et al. (2014). Effect of late planting and shading on cellulose synthesis during cotton fiber secondary wall development. PLoS ONE 9:e105088. doi: 10.1371/journal.pone.0105088

Fu, C., Dan, L., Chen, Y., and Tang, J. (2015). Trends of the sunshine duration and diffuse radiation percentage on sunny days in urban agglomerations of China during 1960-2005. J. Environ. Sci. 34, 206-211. doi: 10.1016/j.jes.2014.08.027

Hirano, K., Kotake, T., Kamihara, K., Tsuna, K., Aohara, T., Kaneko, Y., et al. (2010). Rice BRITTLE CULM 3 (BC3) encodes a classical dynamin OsDRP2B essential for proper secondary cell wall synthesis. Planta 232, 95-108. doi: 10.1007/s00425-010-1145-6

Huber, H., Brouwer, J., Wettberg, E. J., During, H. J., and Anten, N. P. (2014). More cells, bigger cells or simply reorganization? Alternative mechanisms leading to changed internode architecture under contrasting stress regimes. New Phytol. 201, 193-204. doi: 10.1111/nph.12474

Ishimaru, K., Togawa, E., Ookawa, T., Kashiwagi, T., Madoka, Y., and Hirotsu, N. (2008). New target for rice lodging resistance and its effect in a typhoon. Planta 227, 601-609. doi: 10.1007/s00425-007-0642-8

Islam, M. S., Peng, S., Visperas, R. M., Ereful, N., Bhuiya, M. S. U., and Julfiquar, A. (2007). Lodging-related morphological traits of hybrid rice in a tropical irrigated ecosystem. Field Crops Res. 101, 240-248. doi: 10.1016/j.fcr.2006. 12.002

Kambezidis, H., Kaskaoutis, D., Kharol, S. K., Moorthy, K. K., Satheesh, S., Kalapureddy, M., et al. (2012). Multi-decadal variation of the net downward shortwave radiation over south Asia: the solar dimming effect. Atmos. Environ. 50, 360-372. doi: 10.1016/j.atmosenv.2011.11.008

Kashiwagi, T., Togawa, E., Hirotsu, N., and Ishimaru, K. (2008). Improvement of lodging resistance with QTLs for stem diameter in rice (Oryza sativa L.). Theor. Appl. Genet. 117, 749-757. doi: 10.1007/s00122-008-0816-1

Khush, G. S. (1999). Green revolution: preparing for the 21 st century. Genome 42, 646-655. doi: 10.1139/g99-044

Kong, E., Liu, D., Guo, X., Yang, W., Sun, J., Li, X., et al. (2013). Anatomical and chemical characteristics associated with lodging resistance in wheat. Crop J. 1, 43-49. doi: 10.1016/j.cj.2013.07.012

Kotake, T., Aohara, T., Hirano, K., Sato, A., Kaneko, Y., Tsumuraya, Y., et al. (2011). Rice Brittle culm 6 encodes a dominant-negative form of CesA protein that perturbs cellulose synthesis in secondary cell walls. J. Exp. Bot. 62, 2053-2062. doi: $10.1093 /$ jxb/erq395

\section{ACKNOWLEDGMENTS}

We thank the staff of the Key Laboratory of Crop Physiology and Ecology in Southern China, Nanjing Agriculture University. Funding was provided by the National Science and Technology support plan (2015BAD01B03), Jiangsu Province with plans to focus on R\&D priorities (modern agriculture) Project (BE2015337-3), and Fundamental Research Funds for the Central Universities (KYTZ201402). The project was funded by the Priority Academic Program Development of Jiangsu Higher Education Institutions.

Koyama, K., Ikeda, H., Poudel, P. R., and Goto-Yamamoto, N. (2012). Light quality affects flavonoid biosynthesis in young berries of Cabernet Sauvignon grape. Phytochemistry 78, 54-64. doi: 10.1016/j.phytochem.2012.02.026

Li, F., Zhang, M., Guo, K., Hu, Z., Zhang, R., Feng, Y., et al. (2014). High-level hemicellulosic arabinose predominately affects lignocellulose crystallinity for genetically enhancing both plant lodging resistance and biomass enzymatic digestibility in rice mutants. Plant Biotechnol. J. 13, 514-525. doi: 10.1111/pbi. 12276

Li, X., Chen, W., Zhao, Y., Xiang, Y., Jiang, H., Zhu, S., et al. (2013). Downregulation of caffeoyl-CoA O-methyltransferase (CCoAOMT) by RNA interference leads to reduced lignin production in maize straw. Genet. Mol. Biol. 36, 540-546. doi: 10.1590/S1415-47572013005000039

Li, X., Yang, Y., Yao, J., Chen, G., Li, X., Zhang, Q., et al. (2009). FLEXIBLE CULM 1 encoding a cinnamyl-alcohol dehydrogenase controls culm mechanical strength in rice. Plant Mol. Biol. 69, 685-697. doi: 10.1007/s11103-008-9448-8

Liu, H., Yang, C., and Li, L. (2016). Shade-induced stem elongation in rice seedlings: implication of tissue-specific phytohormone regulation. J. Integr. Plant Biol. 58, 614-617. doi: 10.1111/jipb.12468

Liu, J., Linderholm, H., Chen, D., Zhou, X., Flerchinger, G. N., Yu, Q., et al. (2015). Changes in the relationship between solar radiation and sunshine duration in large cities of China. Energy 82, 589-600. doi: 10.1016/j.energy.2015. 01.068

Liu, W., Zou, J., Zhang, J., Yang, F., Wan, Y., and Yang, W. (2015). Evaluation of Soybean (Glycine max) stem vining in maize-soybean relay strip intercropping system. Plant Prod. Sci. 18, 69-75. doi: 10.1626/pps.18.69

Liu, W., and Tollenaar, M. (2009). Response of yield heterosis to increasing plant density in maize. Crop Sci. 49, 1807-1816. doi: 10.1534/g3.112.004630

Livak, K. J., and Schmittgen, T. D. (2001). Analysis of relative gene expression data using real-time quantitative PCR and the $2^{-\Delta \Delta C T}$ method. Methods 25 , 402-408. doi: 10.1006/meth.2001.1262

Ma, Q. (2009). The expression of caffeic acid 3-O-methyltransferase in two wheat genotypes differing in lodging resistance. J. Exp. Bot. 60, 2763-2771. doi: $10.1093 /$ jxb/erp132

Ma, Q. (2010). Functional analysis of a cinnamyl alcohol dehydrogenase involved in lignin biosynthesis in wheat. J. Exp. Bot. 61, 2735-2744. doi: 10.1093/jxb/ erq107

Ma, Q., and Luo, H. (2015). Biochemical characterization of caffeoyl coenzyme A 3-O-methyltransferase from wheat. Planta 242, 113-122. doi: 10.1007/s00425015-2295-3

Mo, Z., Li, W., Pan, S., Fitzgerald, T. L., Xiao, F., Tang, Y., et al. (2015). Shading during the grain filling period increases 2-acetyl-1-pyrroline content in fragrant rice. Rice 8, 9. doi: 10.1186/s12284-015-0040-y

Mou, Z., He, Y., Dai, Y., Liu, X., and Li, J. (2000). Deficiency in fatty acid synthase leads to premature cell death and dramatic alterations in plant morphology. Plant Cell 12, 405-417. doi: 10.1105/tpc.12.3.405

Ookawa, T. (1992). Varietal difference of physical characteristics of the culm related to lodging resistance in paddy rice. Jpn. J. Crop Sci. 61, 419-425. doi: 10.1626/ jcs.61.419

Ookawa, T., Hobo, T., Yano, M., Murata, K., Ando, T., Miura, H., et al. (2010). New approach for rice improvement using a pleiotropic QTL gene for lodging resistance and yield. Nat. Commun. 1, 132. doi: 10.1038/ncomms 1132 
Ookawa, T., Inoue, K., Matsuoka, M., Ebitani, T., Takarada, T., Yamamoto, T., et al. (2014). Increased lodging resistance in long-culm, low-lignin gh2 rice for improved feed and bioenergy production. Sci. Rep. 4:6567. doi: 10.1038/srep06567

Peng, D., Chen, X., Yin, Y., Lu, K., Yang, W., Tang, Y., et al. (2014). Lodging resistance of winter wheat (Triticum aestivum L.): Lignin accumulation and its related enzymes activities due to the application of paclobutrazol or gibberellin acid. Field Crops Res. 157, 1-7. doi: 10.1016/j.fcr.2013.11.015

Ramanathan, V., and Feng, Y. (2009). Air pollution, greenhouse gases and climate change: global and regional perspectives. Atmos. Environ. 43, 37-50. doi: 10.1177/0734242X09350787

Rogers, L. A., Dubos, C., Cullis, I. F., Surman, C., Poole, M., Willment, J., et al. (2005). Light, the circadian clock, and sugar perception in the control of lignin biosynthesis. J. Exp. Bot. 56, 1651-1663. doi: 10.1093/jxb/eri162

Rolland, F., Winderickx, J., and Thevelein, J. M. (2001). Glucose-sensing mechanisms in eukaryotic cells. Trends Biochem. Sci. 26, 310-317. doi: 10.1016/ S0968-0004(01)01805-9

Sattler, S. E., Saathoff, A. J., Haas, E. J., Palmer, N. A., Funnell-Harris, D. L., Sarath, G., et al. (2009). A nonsense mutation in a cinnamyl alcohol dehydrogenase gene is responsible for the sorghum brown midrib6 phenotype. Plant Physiol. 150, 584-595. doi: 10.1104/pp.109.136408

Sparkes, D., and King, M. (2008). Disentangling the effects of PAR and R: FR on lodging-associated characters of wheat (Triticum aestivum). Ann. Appl. Biol. 152, 1-9. doi: 10.1111/j.1744-7348.2007.00184.x

Stanhill, G., and Cohen, S. (2001). Global dimming: a review of the evidence for a widespread and significant reduction in global radiation with discussion of its probable causes and possible agricultural consequences. Agric. For. Meteorol. 107, 255-278. doi: 10.1016/S0168-1923(00)00241-0

Su, G., An, Z., Zhang, W., and Liu, Y. (2005). Light promotes the synthesis of lignin through the production of $\mathrm{H} 2 \mathrm{O} 2$ mediated by diamine oxidases in soybean hypocotyls. J. Plant Physiol. 162, 1297-1303. doi: 10.1016/j.jplph.2005.04.033

Tanaka, K., Murata, K., Yamazaki, M., Onosato, K., Miyao, A., and Hirochika, H. (2003). Three distinct rice cellulose synthase catalytic subunit genes required for cellulose synthesis in the secondary wall. Plant Physiol. 133, 73-83. doi: 10.1104/pp.103.022442

Updegraff, D. M. (1969). Semimicro determination of cellulose inbiological materials. Anal. Biochem. 32, 420-424. doi: 10.1016/S0003-2697(69)80009-6

Wang, C., Hu, D., Liu, X., She, H., Ruan, R., Yang, H., et al. (2015). Effects of uniconazole on the lignin metabolism and lodging resistance of culm in common buckwheat (Fagopyrum esculentum M.). Field Crops Res. 180, 46-53. doi: 10.1016/j.fcr.2015.05.009

Wang, L., Deng, F., and Ren, W.-J. (2015). Shading tolerance in rice is related to better light harvesting and use efficiency and grain filling rate during grain filling period. Field Crops Res. 180, 54-62. doi: 10.1016/j.fcr.2015.05.010

Wang, L., Deng, F., Ren, W.-J., and Yang, W.-Y. (2013). Effects of shading on starch pasting characteristics of indica hybrid rice (Oryza sativa L.). PloS ONE 8:e68220. doi: 10.1371/journal.pone.0068220

Wang, L., Guo, K., Li, Y., Tu, Y., Hu, H., Wang, B., et al. (2010). Expression profiling and integrative analysis of the CESA/CSL superfamily in rice. BMC Plant Biol. 10:282. doi: 10.1186/1471-2229-10-282

Wang, Y., Gao, L., Shan, Y., Liu, Y., Tian, Y., and Xia, T. (2012a). Influence of shade on flavonoid biosynthesis in tea (Camellia sinensis (L.) O. Kuntze). Sci. Hortic. 141, 7-16. doi: 10.1016/j.scienta.2012.04.013

Wang, Y., Gao, L., Wang, Z., Liu, Y., Sun, M., Yang, D., et al. (2012b). Light-induced expression of genes involved in phenylpropanoid biosynthetic pathways in callus of tea (Camellia sinensis (L.) O. Kuntze). Sci. Hortic. 133, 72-83. doi: 10.1016/j.scienta.2011.10.017
Wu, B., Zhang, B., Dai, Y., Zhang, L., Shang-Guan, K., Peng, Y., et al. (2012). Brittle Culm15 encodes a membrane-associated chitinase-like protein required for cellulose biosynthesis in rice. Plant Physiol. 159, 1440-1452. doi: 10.1104/ pp.112.195529

Xue, J., Gou, L., Zhao, Y., Yao, M., Yao, H., Tian, J., et al. (2016). Effects of light intensity within the canopy on maize lodging. Field Crops Res. 188, 133-141. doi: 10.1016/j.fcr.2016.01.003

Yang, X., Asseng, S., Wong, M. T. F., Yu, Q., Li, J., and Liu, E. (2013). Quantifying the interactive impacts of global dimming and warming on wheat yield and water use in China. Agric. For. Meteorol. 182, 342-351. doi: 10.1016/j.agrformet. 2013.07.006

Yoshida, S., Forno, D., Cock, J., and Gomez, K. (1976). "Determination of sugar and starch in plant tissue," in Laboratory Manual for Physiological Studies of Rice, ed. S. Yoshida (Los Baños: The International Rice Research Institute), 46-49.

Yu, J., Qiu, H., Liu, X., Wang, M., Gao, Y., Chory, J., et al. (2015). Characterization of tub4P287L, a $\beta$-tubulin mutant, revealed new aspects of microtubule regulation in shade. J. Integr. Plant Biol. 57, 757-769. doi: 10.1111/jipb. 12363

Zhang, B., Liu, X., Qian, Q., Liu, L., Dong, G., Xiong, G., et al. (2011). Golgi nucleotide sugar transporter modulates cell wall biosynthesis and plant growth in rice. Proc. Natl. Acad. Sci. U.S.A. 108, 5110-5115. doi: 10.1073/pnas. 1016144108

Zhang, J., Li, G., Song, Y., Liu, Z., Yang, C., Tang, S., et al. (2014). Lodging resistance characteristics of high-yielding rice populations. Field Crops Res. 161, 64-74. doi: 10.1016/j.fcr.2014.01.012

Zhang, M., Zhang, B., Qian, Q., Yu, Y., Li, R., Zhang, J., et al. (2010). Brittle Culm 12, a dual-targeting kinesin-4 protein, controls cell-cycle progression and wall properties in rice. Plant J. 63, 312-328. doi: 10.1111/j.1365-313X.2010. 04238.x

Zhang, W., Wu, L., Ding, Y., Wen, F., Wu, X., Li, G., et al. (2016a). Topdressing nitrogen fertilizer rate contributes to decrease culm physical strength by reducing structural carbohydrate content in japonica rice. J. Integr. Agric. 15, 992-1004. doi: 10.1016/S2095-3119(15)61166-2

Zhang, W., Wu, L., Wu, X., Ding, Y., Li, G., Li, J., et al. (2016b). Lodging resistance of japonica rice (Oryza Sativa L.): morphological and anatomical traits due to top-dressing nitrogen application rates. Rice 9, 31. doi: 10.1186/s12284-0160103-8

Zhou, Y., Li, S., Qian, Q., Zeng, D., Zhang, M., Guo, L., et al. (2009). BC10, a DUF266-containing and Golgi-located type II membrane protein, is required for cell-wall biosynthesis in rice (Oryza sativa L.). Plant J. 57, 446-462. doi: $10.1111 / j .1365-313 X .2008 .03703 . x$

Zuber, U., Winzeler, H., Messmer, M., Keller, M., Keller, B., Schmid, J., et al. (1999). Morphological traits associated with lodging resistance of spring wheat (Triticum aestivum L.). J. Agron. Crop Sci. 182, 17-24. doi: 10.1046/j.1439-037x. 1999.00251.x

Conflict of Interest Statement: The authors declare that the research was conducted in the absence of any commercial or financial relationships that could be construed as a potential conflict of interest.

Copyright (c) 2017 Wu, Zhang, Ding, Zhang, Cambula, Weng, Liu, Ding, Tang, Chen, Wang and Li. This is an open-access article distributed under the terms of the Creative Commons Attribution License (CC BY). The use, distribution or reproduction in other forums is permitted, provided the original author(s) or licensor are credited and that the original publication in this journal is cited, in accordance with accepted academic practice. No use, distribution or reproduction is permitted which does not comply with these terms. 